\title{
A PARAMATERIC MODEL FOR SOLID OXIDE FUEL CELLS BASED ON MEASUREMENTS MADE ON CELL MATERIALS AND COMPONENTS
}

\author{
Liangzhu Zhu ${ }^{\mathrm{a}}$, Lei Zhang ${ }^{\mathrm{a}}$ and Anil V. Virkar ${ }^{\mathrm{a},{ }^{*}}$ \\ ${ }^{a}$ Department of Materials Science \& Engineering, University of Utah \\ Salt Lake City, UT 84112, USA
}

*Corresponding Author, Phone: (801) 581-5396, Email: anil.virkar@ utah.edu

A parametric equation describing polarization in solid oxide fuel cells (SOFC) in terms of experimentally measurable parameters is presented. The equation explicitly describes activation and concentration polarizations at the two electrodes and the ohmic loss as functions of current density. Using known values of parameters measured on cell materials and components, various polarizations are estimated as functions of current density and the possible performance characteristics are assessed. The calculated performance curves using measurements made on cell materials and components are in good agreement with actual fuel cell tests. Using the model, prospects for ultra-high power density SOFC at 
intermediate temperatures $\left(<800^{\circ} \mathrm{C}\right)$ are examined. The results show that even in thin electrolyte film anode-supported cells, the ohmic contribution can be substantial, not all of it being attributable to electrolyte and electrode materials. The results also show that the electrode particle size has a substantial effect on the activation polarization.

Key Words: Solid oxide fuel cells, modeling, parametric equation, high performance.

\section{INTRODUCTION}

Considerable work has been reported on solid oxide fuel cells (SOFC) over the past couple of decades $[1,2,3]$. Various materials for the three components, namely cathode, electrolyte and anode, have been investigated over the past 30+ years. The state-of-the-art materials for SOFC are: 8 mol. $\% \mathrm{Y}_{2} \mathrm{O}_{3}$-stabilized zirconia (YSZ) for the electrolyte, as a constituent in porous $\mathrm{Ni}+$ YSZ composite anode and as a constituent in porous Sr-doped $\mathrm{LaMnO}_{3}(\mathrm{LSM})+\mathrm{YSZ}$ composite cathode. Much of the early work was based on using porous LSM as the cathode without YSZ dispersed in it. Over the last couple of decades many other highly active cathodes have emerged, the vast majority of them being mixed ionic electronic conducting (MIEC) perovskites containing transition metals capable of exhibiting multiple valence states. Much of the early work was also based on using YSZ 
plates of 150 to 200 microns in thickness (or in some cases even thicker) for the electrolyte with screen-printed anode and cathode. Such cells are referred to as electrolyte-supported cells. In order to minimize the ohmic contribution to the total cell resistance such cells have to be operated at high temperatures, typically $\sim 900$ to $1000^{\circ} \mathrm{C}$, to ensure reasonable performance $\left(\sim 0.25 \mathrm{Wcm}^{-2}\right)$. The use of single phase LSM also leads to generally poor cathode performance at temperatures below $900^{\circ} \mathrm{C}$. High temperature operation poses significant challenges related to materials degradation especially when used in a planar geometry and with a metallic interconnect.

In subsequent work in this field processes were developed for fabricating cells comprising thin YSZ electrolyte film supported on a porous electrode (typically the anode). This allowed for a significant lowering of the total ohmic contribution thereby enhancing performance. Using state-of-the-art materials maximum power densities approaching $2 \mathrm{Wcm}^{-2}$ at a temperature as low as $800^{\circ} \mathrm{C}$ were demonstrated in anodesupported button cells [2,3]. This represented not only an order of magnitude improvement in performance but that too at a temperature 200 degrees lower. Many SOFC researchers have been involved in developing such high performance thin electrolyte, electrode-supported cells at lower operating temperatures over the past couple of decades. Further improvements in performance can be realized by using other perovskite cathodes, especially those containing $\mathrm{Co}$ and $\mathrm{Fe}$ as B-site constituents exhibiting mixed ionic electronic conducting (MIEC) properties. It is to be emphasized, however, that fine-grained two-phase LSM + YSZ (or LSM + rare earth oxide doped ceria) cathodes perform nearly as well as many single phase LSC and LSF-based 
cathodes assuming suitable microstructures have been developed. Also, some of the highest performance reported to date has been on cells made with composite cathodes. Finally, the lowering of the ohmic contribution requires the use of electrolyte materials with higher ionic conductivity than YSZ. These materials include scandia-stabilized zirconia (ScSZ), Sr-doped and $\mathrm{Mg}$-doped $\mathrm{LaGaO}_{3}$ (LSGM) and rare earth oxide doped ceria. Limited amount of work has been reported on SOFCs made with these other electrolyte materials in a thin film form.

While much progress has been made it also appears that there have not been significant further gains in performance, beyond those achieved about fifteen years ago. One of the difficulties has been in accurately measuring the various polarization losses which has made it challenging to target those areas requiring more effort. There are five sources of voltage loss: (a) Ohmic loss - voltage loss associated with the electrolyte, the electrodes and contact regions between the electrodes and the electrolyte; (b) Concentration polarization at the cathode - voltage loss associated with the transport of the oxidant through the porous cathode, (c) Concentration polarization at the anode - voltage loss associated with the transport of the fuel through the porous anode, (d) Activation polarization at the cathode - voltage loss associated with the electrochemical reduction of the active constituent in the oxidant (oxygen) and (e) Activation polarization at the anode - voltage loss associated with the electrochemical oxidation of the active constituent in the fuel (typically hydrogen). The activation polarization involves a number of series steps such as gas adsorption, dissociation, electron transfer and transfer of ionic species into (or out of) the electrolyte at the electrode catalyst (e.g. LSM)/electrolyte (e.g. YSZ) 
interface. In a typical cell it is usually difficult to separately measure anode and cathode polarization losses and also it is equally difficult to experimentally separate out concentration and activation polarization losses at either of the two electrodes. The most commonly used technique is electrochemical impedance spectroscopy (EIS). Almost always the EIS spectra overlap and it is often not possible to unequivocally determine the various contributions. And even if the EIS spectra can be described using a number of equivalent circuits it is generally difficult to assure uniqueness (multiple equivalent circuits can be used to describe a given experimental data set thus making physical interpretation difficult). It appears that to realize further improvements in cell performance may require accurate identification of the various polarization losses, their sources and their dependence on material and microstructural parameters, atmosphere and temperature. The objective of this work is to use a parametric model for SOFC [4], quantitatively estimate the various polarization losses based on measurements made on cell materials and components and determine what parameters may need to be optimized to improve the performance, beyond what has been achieved to date.

\section{A PARAMETRIC MODEL FOR SOFC}

Several models which take into account gas transport through porous electrodes, electrochemical reactions at the electrodes (near electrode/electrolyte interfaces) including various reaction steps and the ohmic loss have been developed [5-11]. The vast 
majority of them, however, are numerical in nature due to the analytical complexities involved. Also, the vast majority of the models are based on many assumed parameters regarding the microstructure of the electrodes, assumed chemical reaction steps and parameters related to the reaction steps (e.g. an assumed rate determining step). Thus, quantitative validation of virtually all of these models is impossible for lack of experimentally verifiable/measurable parameters used in many of the models. The main difficulty lies in the fact that multiple assumed parameters are required for modeling, while the experimental voltage vs. current density traces are featureless. As a consequence, the inverse problem of determining the various parameters from the measured cell performance curves lacks uniqueness. Essentially the same difficulty arises in the use of EIS on actual cells since the inverse problem of determining various cell parameters from EIS spectra lacks uniqueness.

It appears that an approach of using a parametric model which is based on parameters that can be experimentally measured on cell materials and components, at least in principle, could be the first step towards developing a thorough understanding of the various voltage losses that occur in a typical SOFC [4]. Calculation of cell performance curves based on measured parameters on cell materials and cell components is a forward problem, and thus in principle it has a unique solution for a given set of parameters [12]. It is understood, however, that there usually will be multiple sets of different parameters which can give the same cell performance. Such an approach can estimate the dominant sources of voltage losses thus identifying areas which require further work in order to increase the performance. Detailed numerical modeling may then be the next step to 
allow for the inclusion of multi-dimensional features in addition to issues such as fuel utilization and non-isothermal operation.

A typical anode-supported SOFC consists of at least five distinct layers: (a) A porous anode-support characterized by high electronic conductivity to minimize the ohmic loss and high porosity for easy transport of gaseous fuel (to minimize anode concentration polarization); (b) A porous anode functional layer adjacent to the electrolyte characterized by fine microstructure for enhanced electrocatalysis (electrochemical oxidation of fuel; lowering of the anode activation polarization); (c) A dense, thin (to minimize the ohmic loss) film electrolyte; (d) A porous cathode functional layer adjacent to the electrolyte characterized by fine microstructure for enhanced electrocatalysis (electrochemical reduction of the oxidant; lowering of the cathode activation polarization); and (e) A porous cathode current collector layer characterized by high electronic conductivity to minimize the ohmic loss and high porosity for easy transport of the oxidant (to minimize cathode concentration polarization). In a parametric model voltage vs. current density polarization curves of an SOFC may be adequately described by a generic equation of the form $[3,13]$

$$
V(i)=E_{o}-i R_{i}-\eta_{\text {act }}^{a}-\eta_{\text {act }}^{c}-\eta_{\text {conc }}^{a}-\eta_{\text {conc }}^{c}
$$

In Equation (1) $E_{o}$ is the open circuit voltage, $i$ is the current density, $R_{i}$ is the ohmic area specific resistance $\left(\Omega \mathrm{cm}^{2}\right), \eta_{a c t}^{a}$ is the activation polarization at the anode, $\eta_{a c t}^{c}$ is the activation polarization at the cathode, $\eta_{c o n c}^{a}$ is the concentration polarization at the 
anode and $\eta_{\text {conc }}^{c}$ is the concentration polarization at the cathode. The voltage vs. current density polarization curves may further be described by $[3,13]$

$$
V(i)=E_{o}-i R_{i}-\eta_{a c t}^{a}-\eta_{a c t}^{c}+\frac{R T}{2 F} \ln \left(\frac{p_{H_{2}}^{\prime}(i) p_{H_{2} O}^{o}}{p_{H_{2}}^{o} p_{H_{2} O}^{\prime}(i)}\right)+\frac{R T}{4 F} \ln \left(\frac{p_{O_{2}}^{\prime}(i)}{p_{O_{2}}^{o}}\right)
$$

in which the $\eta_{\text {conc }}^{a}$ is given in terms of partial pressures of hydrogen and water vapor on the anode side and $\eta_{c o n c}^{c}$ is given in terms of oxygen partial pressures on the cathode side. In equation (2) $R$ is the gas constant, $F$ is the Faraday constant, $T$ is the temperature, $p_{\mathrm{H}_{2}}^{o}$ is the partial pressure of hydrogen in the fuel just outside the anode, $p_{H_{2}}^{\prime}(i)$ is the partial pressure of hydrogen in the anode close to the anode functional layer/electrolyte interface, $p_{\mathrm{H}_{2} \mathrm{O}}^{o}$ is the partial pressure of water vapor just outside the anode, $p_{\mathrm{H}_{2} \mathrm{O}}^{\prime}(i)$ is the partial pressure of water vapor in the anode close to the anode functional layer/electrolyte interface, $p_{\mathrm{O}_{2}}^{o}$ is the partial pressure of oxygen just outside the cathode and $p_{\mathrm{O}_{2}}(i)$ is the partial pressure of oxygen in the cathode close to the cathode functional layer/electrolyte interface. In some cases the activation polarization may be combined into a single equation described by the phenomenological Tafel equation, $\eta_{a c t}=a+b \ln i$, where $a$ and $b$ are the Tafel constants. The Tafel equation is valid only beyond some phenomenological exchange current density, $i_{o}$. The parameters $a$ and $b$ include contributions from both the anode and the cathode. Equation (2) albeit simple embodies essentially all relevant features inclusive of all voltage losses in a quantitative manner and provides a platform for relating cell performance to parameters measured on cell materials and components. Also note that all terms on the right side are 
expressed as functions of the current density, $i$, which is an experimentally controllable and a measureable parameter.

Equation (1) shows that the absolute minimum number of independent parameters required to describe cell performance of a five layer cell is nine; a minimum of four parameters describing gas transport through the four porous layers whose porosities and microstructures can be independently varied (selected), four parameters which describe the total activation polarization at the two electrodes (wherein each activation polarization contains two independent parameters - exchange current density and transfer coefficient) and the ohmic contribution of the entire cell. However, virtually all experimentally measured voltage vs. current density plots are featureless and can be readily described as a polynomial in current density $i$ containing no more than two or three terms. This means regardless of the science of the problem only two or three fitting parameters are required to describe the voltage vs. current density plots. But the independent parameters are at least nine. This means it is not possible to obtain a unique set of nine parameters from cell performance curves when the phenomenological fit requires only two or three. This is the fundamental challenge related to the lack of uniqueness in this inverse problem. This is illustrated via an example of typical, experimentally measured voltage vs. current density traces on a cell shown in Figure 1(a) [13]. The data were obtained at $800^{\circ} \mathrm{C}, 700^{\circ} \mathrm{C}$ and $600^{\circ} \mathrm{C}$ [13]. The activation polarization at the two electrodes, the concentration polarizations at the two electrodes and the total cell ohmic resistance contribute to the observed cell performance. Their quantitative description entails a minimum of nine independent parameters. Figure 1(b) shows 
polynomial fits to the data at $800^{\circ} \mathrm{C}$ with the order ranging between 2 and 9 . As seen in the figure, there is hardly any difference among the various fits and that that a $2^{\text {nd }}$ order polynomial empirical fit describes the experimental data set quite well.

In general a polynomial fit to a voltage, $V(i)$, vs. current density, $i$, plot may be given by

$$
V(i)=\sum_{k=0}^{n} a_{k} i^{k}=a_{o}+a_{1} i+a_{2} i^{2} \ldots+a_{k} i^{k}+\ldots+a_{n} i^{n}
$$

Table 1 gives the coefficients for the polynomial fits and the corresponding least squares error at $800^{\circ} \mathrm{C}$. Table 1 shows that the coefficients $a_{1}$ range between -0.344 and -0.667 for polynomial fits of order 2 to 9 . The coefficient $a_{1}$ includes the ohmic and linear terms of other polarizations. The rmse values range between 0.0057 and 0.0015 . The table thus shows that a wide range in parameters can lead to essentially identical fits and it is not possible to obtain unique set of fundamental parameters by fitting to cell test data. It also means that good fit to cell test data can be obtained by multiple choices of the various parameters, often varying over a wide range.

By comparing equation (1) with equation (3) and using Taylor series expansion of equation (1) around $i=0$, note that

$$
a_{o}=E_{o}
$$




$$
a_{1}=-R_{i}-\left(\left.\frac{d \eta_{a c t}^{a}}{d i}\right|_{i=0}+\left.\frac{d \eta_{a c t}^{c}}{d i}\right|_{i=0}+\left.\frac{d \eta_{c o n c}^{a}}{d i}\right|_{i=0}+\left.\frac{d \eta_{c o n c}^{c}}{d i}\right|_{i=0}\right)
$$

and

$$
a_{k}=-\frac{1}{k !}\left(\left.\frac{d^{k} \eta_{a c t}^{a}}{d i^{k}}\right|_{i=0}+\left.\frac{d^{k} \eta_{a c t}^{c}}{d i^{k}}\right|_{i=0}+\left.\frac{d^{k} \eta_{c o n c}^{a}}{d i^{k}}\right|_{i=0}+\left.\frac{d^{k} \eta_{c o n c}^{c}}{d i^{k}}\right|_{i=0}\right)
$$

The first coefficient, $a_{o}=E_{o}$, is readily obtained from experimental cell test data as the open circuit voltage or can be calculated as the Nernst voltage (if electronic conduction through the cell is negligible). The coefficient $a_{1}$ contains the ohmic resistance $\left(R_{i}\right)$ and contributions from the activation and the concentration polarizations and thus contains up to nine unknown parameters. All other higher order coefficients $\left(a_{k}\right.$ for $\left.k \geq 2\right)$ include up to eight unknown parameters. If analytical forms of the various polarizations are known, which is rarely the case, analytical forms of the various coefficients can in principle be obtained. For example if the activation polarization at an electrode can be described using the Butler-Volmer equation, namely

$$
i=i_{o}\left\{\exp \left[-\frac{\alpha z F \eta_{a c t}}{R T}\right]-\exp \left[\frac{(1-\alpha) z F \eta_{a c t}}{R T}\right]\right\}
$$

the first two derivatives are given as follows

$$
\left.\frac{d \eta_{a c t}}{d i}\right|_{i=0}=\frac{R T}{z F i_{o}}
$$

and 


$$
\left.\frac{d^{2} \eta_{a c t}}{d i^{2}}\right|_{i=0}=-\frac{(1-2 \alpha) R T}{z F i_{o}^{2}}
$$

Similar equations can be given for concentration polarizations. Thus all coefficients in a polynomial fit have a fundamental origin. However, the exact forms of the various polarizations are generally not known. If one were to fit voltage vs. current density plots using a polynomial and if an excellent fit can be obtained to a polynomial of order 3 , it means it is not possible to obtain 9 unique parameters by fitting to experimental cell test data. This also means the validity of any analytical/numerical model cannot be judged merely on the basis of the goodness of fit to experimental cell test data regardless of how detailed and sophisticated a model may be. These difficulties are central to all inverse problems [12]. Thus, what we propose to solve here is the forward problem. That is, for a given set of parameters that can be measured on cell materials and cell components, the objective is to estimate cell performance that can be realized, given cell dimensions and microstructural details of the electrodes.

In the anode support and the cathode current collector the electrical current is essentially electronic and the corresponding gaseous fluxes are independent of position, assuming no internal reforming. However, over the thicknesses of the functional layers the current consists of two components - electronic and ionic with the total current being fixed; it varies from (nearly) purely ionic at the interface between the electrolyte and the functional layer to (nearly) purely electronic just outside the functional layers (into the current collectors). As a result gaseous fluxes depend on position within the functional 
layers. The typical thicknesses of the functional layers are $\sim 10$ to 25 microns. The analytical model given in equation (2) ignores this aspect.

In what follows three types of voltage losses or polarizations relevant to an SOFC are examined. They are: (1) Ohmic loss (occurs through the entire cell), (2) Activation polarization (occurs at both electrodes) and (3) Concentration polarization (occurs at both electrodes).

\section{Sources of Voltage Loss:}

Ohmic Loss: It is often customary to attribute most of the cell ohmic contribution to the electrolyte since the electrolyte ionic resistivity is much greater than the electronic resistivities of the electrodes. In thin electrolyte film anode-supported cells, however, this assumption may not always be satisfactory. That is ohmic contributions from the other components to the net cell ohmic area specific resistance may not be negligible. The ohmic contribution in general may be given by [13]

$$
R_{i}=\rho_{e}^{\text {ionic }} l_{e}+\rho_{c(1)}^{\text {elect }} l_{c(1)}+\rho_{c(2)}^{\text {elect }} l_{c(2)}+\rho_{a(1)}^{\text {elect }} l_{a(1)}+\rho_{a(2)}^{\text {elect }} l_{a(2)}+R_{\text {contact }}
$$

where $\rho_{e}^{i o n i c}$ is the ionic resistivity of the electrolyte, $l_{e}$ is the electrolyte thickness, $\rho_{c(1)}^{\text {elect }}$ is the electronic resistivity of the cathode current collector, $l_{c(1)}$ is the cathode current collector layer thickness, $\rho_{c(2)}^{\text {elect }}$ is the electronic resistivity of the cathode 
functional layer, $l_{c(2)}$ is the cathode functional layer thickness, $\rho_{a(1)}^{\text {elect }}$ is the electronic resistivity of the anode support, $l_{a(1)}$ is the anode support thickness, $\rho_{a(2)}^{\text {elect }}$ is the electronic resistivity of the anode functional layer, $l_{a(2)}$ is the anode functional layer thickness and $R_{\text {contact }}$ is the contact resistance associated with the interfaces between the various layers. The contact resistance is a function of the nature of contact between the layers; the poorer the contact (such as due to the presence of narrow inter-particle necks or due to the presence of lateral voids or cracks along and parallel to interfaces) - the higher is this contribution. Analysis of cell microstructures reported in several studies shows that cracks or elongated regions at electrolyte/electrode interfaces are quite common [14]. These cracks or elongated regions (or partial delaminations) are thought to contribute to the contact resistance, which is not accounted for in the sum of the individual layer resistances. The results in many studies (typically EIS spectra) also show that the ohmic contribution is much larger than can be accounted for on the basis of component resistances. The possible formation of a thin layer of $\mathrm{La}_{2} \mathrm{Zr}_{2} \mathrm{O}_{7}$ and $\mathrm{SrZrO}_{3}$ at the cathode/electrolyte interface is an additional, major source of contact resistance [15]. It thus appears that contact resistances across interfaces can be significant contributors to the overall cell area specific resistance. In this context the nature of an interface between two adjacent layers may have a significant effect on the net ohmic contribution. In principle this contribution may be estimated by solving the appropriate boundary value problems (such as solution to the Laplace equation for mixed boundary conditions) if the geometry of the cracks or the voids is known and/or by measuring interface reaction layer resistivity and thickness formed between the cathode and the electrolyte. The resistivities 
of various regions can be independently (experimentally) measured. This has been done for the anode support, the cathode interlayer and the electrolyte thickness in one study [13]. However, with the exception of this study little information is available in the open literature. According to this one study the total ohmic loss at $800^{\circ} \mathrm{C}$ for an anodesupported cell with YSZ electrolyte, LSM + YSZ cathode and Ni + YSZ anode (of given compositions, porosities and microstructures) used in that study is given as [13]

$$
R_{i}=24 l_{e}+3.92 l_{c(2)}+0.24 l_{a(1)}+R_{c o n s t}^{\prime}
$$

wherein

$$
R_{\text {const }}^{\prime}=\rho_{c(1)}^{\text {elect }} l_{c(1)}+\rho_{a(2)}^{\text {elect }} l_{a(2)}+R_{\text {contact }}
$$

The thicknesses of the layers have units of $\mathrm{cm}$ in equations (11) and (12). The experimentally measured area specific resistance (ASR) in [13] for a cell with $8 \mu \mathrm{m}$ thick YSZ electrolyte was $\sim 0.104 \Omega \mathrm{cm}^{2}$. Equation (11) is valid only at $800^{\circ} \mathrm{C}$ and that too for the particular cells used in that study. It is, however, possible to obtain estimates of the ohmic contributions from the various layers using data reported in the literature on the temperature dependence of electrical conductivities of the various materials used. This is discussed in what follows.

For a cell containing $\mathrm{Ni}+\mathrm{YSZ}$ in both the anode support and the anode functional layer, their total resistivities are expected to increase with temperature because the conducting phase is mainly metallic Ni. With both phases being contiguous electrical conduction 
through the metallic phase dominates. For these two layers their resistivities may be described by the following empirical equation

$$
\frac{1}{\sigma}=\rho=\rho_{o}+\gamma T
$$

where $\rho_{o}$ is the resistivity at the reference temperature of $0 \mathrm{~K}$ and $\gamma$ is the temperature coefficient of resistivity in $\Omega \mathrm{cmK}^{-1}$. Experimental measurements on the effect of temperature on the total electrical resistivity of $\mathrm{Ni}+\mathrm{YSZ}$ over a range of compositions have been reported by Anselmi-Tamburini et al. [16] and Marinsek et al. [17]. Data from these studies are plotted in Figure 2. As seen in the figure the plots of resistivity vs. temperature are linear over the range of temperatures the measurements were made. In our studies the volume fraction of $\mathrm{Ni}$ was $\sim 35$ vol.\% for an anode support layer with 48 vol.\% porosity [13]. No data are available on samples with 35 vol.\% Ni. However, data are available for samples with $38 \mathrm{vol} . \% \mathrm{Ni}[16,17]$. We will use the data corresponding to 38 vol. $\%$ Ni from Figure 2 for the present calculations. Thus the line corresponding to 38 vol.\% Ni in Figure 2 is used to determine $\rho_{o}$ and $\gamma$ for the anode support. For the anode functional layer we will use data for $23 \%$ porosity through which the $\mathrm{H}_{2}-\mathrm{H}_{2} \mathrm{O}$ binary effective diffusivity is available. The line corresponding to 26 vol.\% Ni in Figure 2 was selected for the estimation of the ohmic contribution of the anode functional layer.

For the rest of the cell components the electrical resistivities exhibit an Arrhenius behavior [18-23]. Thus the electrical conductivities sharply increase with increasing temperature (electrical resistivities sharply decrease with increasing temperature). The electrical conductivity may be given by an Arrhenius equation of the form 


$$
\sigma=\frac{\sigma_{o}}{T} \exp \left[-\frac{Q}{R T}\right]
$$

where $Q$ is the activation energy for conduction, $\sigma_{o}$ is the pre-exponential factor in units of $\mathrm{Scm}^{-1} \mathrm{~K}, R$ is the gas constant and $T$ is the temperature in $\mathrm{K}$. A plot of $\ln (\sigma T)$ vs. $1 / T$ should be linear with slope equal to $-\frac{Q}{R}$ and intercept equal to $\ln \left(\sigma_{o}\right)$. In the following calculations we will use two different materials for the electrolyte; YSZ and $\mathrm{Gd}_{2} \mathrm{O}_{3^{-}}$ doped $\mathrm{CeO}_{2}$ (GDC) for which data on ionic conductivities as a function of temperature are well established. The cathode functional layer is selected as $50 \mathrm{vol} \% \mathrm{LSM}+50$ vol.\% YSZ and the cathode current collector is selected as porous LSM. Table 2 lists the equations used to estimate the ohmic contributions of the various layers. At any given temperature the ohmic contributions are estimated for all five layers. In the present calculations even with GDC as the electrolyte, the anode and the anode functional layers selected are $\mathrm{Ni}+\mathrm{YSZ}$ and the cathode current collector and the cathode functional layer contain LSM and LSM + YSZ, respectively. The reason the same materials for the anode and the cathode used for the YSZ electrolyte based cells are also selected for the GDC electrolyte based cells is because property measurements are available only for these two sets of materials.

The Contact Resistance: The origin of the 'contact resistance', $R_{\text {contact }}$, lies in the differing microstructures across the various interfaces which may lead to delaminations or voids or cracks at interfaces across which no current flows, and the possible formation of a resistive layer at the cathode/electrolyte interface, most notably $\mathrm{La}_{2} \mathrm{Zr}_{2} \mathrm{O}_{7}$ [15]. This effectively adds to the ohmic contribution. The $R_{\text {contact }}$ can in principle be measured by 
direct experiments wherein samples of different layer thicknesses can be made but with the same interface (or by measuring the resistance at various positions on either side of the interface and extrapolating the two segments to the interface). No such measurements appear to be available in the literature. Even though detailed information on the contact resistance between cell components, e.g. contact resistance between anode support and anode functional layer, or between electrolyte and cathode functional layer does not appear to have been reported, a model which predicts the contact resistance between anode and interconnect as well as between cathode and interconnect has been proposed by Dey et al. [24]. Their model showed good agreement with their experimental results given in [24] in which detailed morphology of the electrodes and contact with the interconnects such as the contact radius for a single asperity, summit radius, height of an asperity and the inter-planar spacing were taken into account. Their study also showed that the contact resistance initially decreased rapidly with increasing externally applied pressure between the two layers and then saturated at larger pressures. Under an optimum pressure the measured contact resistances at $800^{\circ} \mathrm{C}$ between the anode and the interconnect and between the cathode and the interconnect were $0.048 \Omega \mathrm{cm}^{2}$ and 0.033 $\Omega \mathrm{cm}^{2}$, respectively. These two values changed by a factor of less than two in the temperature range from 600 to $800^{\circ} \mathrm{C}$.

In [13] the authors measured the ohmic resistance as a function of the thickness of the YSZ electrolyte, the Ni + YSZ anode support and the LSM + YSZ cathode functional layer. The resistivity of the corresponding layer was given by the slope. In all three plots the intercepts were nonzero and positive [13]. Their magnitudes were respectively 0.087 , 
0.084 and $0.095 \Omega \mathrm{cm}^{2}$ which all showed that there was some contact resistance in addition to the contributions from the various layers. However, because these authors did not measure the resistivities of the remaining two layers, namely, the anode functional layer and the cathode current collector, they were unable to estimate the contact resistance contribution to their cells. If we use the conductivity formulas in Table 2 for the anode functional layer and the cathode current collector obtained from the literature by using equations (11) and (12), the ohmic loss from the five layers can be calculated. The calculations show that the electrolyte and the anode support dominate the ohmic contribution. Therefore, in what follows we calculate the ohmic resistances for cells of the same geometries as given in [13] and the results are compared in Table 3. As seen in Table 3 the calculated contact resistances from eight different cells range from $39 \%$ to $57 \%$ of the total ohmic resistance with the average being about $48 \%$ and a standard deviation of about $7 \%$. It is also to be noted that the calculated resistances have about the same magnitudes as those measured by Dey et al. [24]. This shows that for the five layer cell the contact resistance attributed to the various interfaces is approximately $50 \%$ of the total ohmic resistance. Thus, in the following calculations we will assume that the contact resistance is about $50 \%$ of the total cell ohmic resistance which includes the possible existence of cracks along interfaces and the possible formation of resistive layers such as $\mathrm{La}_{2} \mathrm{Zr}_{2} \mathrm{O}_{7}$

Concentration Polarization: In what follows concentration polarizations at the cathode and at the anode are estimated using the measured effective binary diffusivities. It is 
assumed that the somewhat higher tortuosity factors ( $\sim 6$ to 10$)$, typically obtained by fitting polarization curves, are the result of the neglect of Knudsen diffusion [25]. The use of the measured effective diffusivities is deemed more accurate than assuming a multiple of unknown parameters such as the tortuosity factor, the pore size and the possible role of surface diffusion along the pore surfaces done in some modeling studies. Also, the rationale is that the effective diffusivities can be experimentally measured but the tortuosity factors or the pore sizes (which need to be used in the approximate estimation of effective Knudsen diffusivities) are not easily measurable. In addition the pores are not of uniform shape and size. For this reason an approach of using effective diffusivities is deemed satisfactory as these can be experimentally measured. The concentration polarization at the cathode is given by $[3,13]$

$$
\eta_{\text {conc }}^{c}=-\frac{R T}{4 F} \ln \left(\frac{p_{O_{2}}^{\prime}(i)}{p_{O_{2}}^{o}}\right)
$$

where $p_{O_{2}}^{o}$ is the partial pressure of oxygen just outside the cathode, $p_{O_{2}}^{\prime}(i)$ is the partial pressure of oxygen in the cathode functional layer close to the cathode functional layer/electrolyte interface and $p$ is the total pressure at the cathode. The $p_{O_{2}}^{\prime}(i)$ for a two layer cathode can be calculated by [13]

$$
p_{O_{2}}^{\prime}(i) \approx p_{O_{2}}^{o}-\left(\frac{i R T}{4 F p}\right)\left[\left(p-p_{O_{2}}^{o}\left(\frac{l_{c(1)}}{D_{O_{2}-N_{2}}^{e f f(1)}}+\frac{l_{c(2)}}{D_{O_{2}-N_{2}}^{e f f(2)}}\right)+\frac{\left(p-p_{O_{2}}^{o}\right)}{p}\left(\frac{i R T l_{c(1)} l_{c(2)}}{4 F D_{O_{2}-N_{2}}^{e f f(1)} D_{O_{2}-N_{2}}^{e f f(2)}}\right)\right]\right.
$$

where $l_{c(1)}$ and $l_{c(2)}$ are respectively the cathode current collector and the cathode functional layer thicknesses, $D_{\mathrm{O}_{2}-N_{2}}^{\text {eff }(1)}$ and $D_{\mathrm{O}_{2}-N_{2}}^{\text {eff (2) }}$ are respectively the effective binary 
diffusivities through the cathode current collector and the cathode functional layer and $p$ is the total oxidant pressure (the sum of oxygen and nitrogen partial pressures).

The anode concentration polarization is similarly given be

$$
\eta_{\text {conc }}^{a}=-\frac{R T}{2 F} \ln \left(\frac{p_{\mathrm{H}_{2}}^{\prime}(i) p_{\mathrm{H}_{2} \mathrm{O}}^{o}}{p_{\mathrm{H}_{2}}^{o} p_{\mathrm{H}_{2} \mathrm{O}}^{\prime}(i)}\right)
$$

where $p_{H_{2}}^{o}$ is the partial pressure of hydrogen in the fuel just outside the anode, $p_{H_{2}}^{\prime}(i)$ is the partial pressure of hydrogen in the anode functional layer close to the anode functional layer/electrolyte interface, $p_{\mathrm{H}_{2} \mathrm{O}}^{o}$ is the partial pressure of water vapor just outside the anode and $p_{\mathrm{H}_{2} \mathrm{O}}^{\prime}(i)$ is the partial pressure of water vapor in the anode functional layer close to the anode functional layer/electrolyte interface. The $p_{H_{2}}^{\prime}(i)$ and $p_{\mathrm{H}_{2} \mathrm{O}}^{\prime}(i)$ for a two layer anode are given respectively by [13]

$$
p_{H_{2}}^{\prime}(i)=\frac{l_{a(2)}}{D_{H_{2}-H_{2} O}^{e f f(2)}}\left[\frac{p_{H_{2}}^{o} D_{H_{2}-H_{2} O}^{e f f(2)}}{l_{a(2)}}-\frac{i R T l_{a(1)}}{2 F D_{H_{2}-H_{2} O}^{e f f(1)}}\left(\frac{D_{H_{2}-H_{2} O}^{e f f(2)}}{l_{a(2)}}+\frac{D_{H_{2}-H_{2} O}^{e f f(1)}}{l_{a(1)}}\right)\right]
$$

and

$$
p_{\mathrm{H}_{2} \mathrm{O}}^{\prime}(i)=\frac{l_{a(2)}}{D_{\mathrm{H}_{2}-H_{2} O}^{e f f(2)}}\left[\frac{p_{\mathrm{H}_{2} O}^{o} D_{H_{2}-H_{2} O}^{e f f(2)}}{l_{a(2)}}+\frac{i R T l_{a(1)}}{2 F D_{H_{2}-H_{2} O}^{e f f(1)}}\left(\frac{D_{H_{2}-H_{2} O}^{e f f(2)}}{l_{a(2)}}+\frac{D_{H_{2}-H_{2} O}^{e f f(1)}}{l_{a(1)}}\right)\right]
$$

where $l_{a(1)}$ and $l_{a(2)}$ are respectively the anode support and the anode functional layer

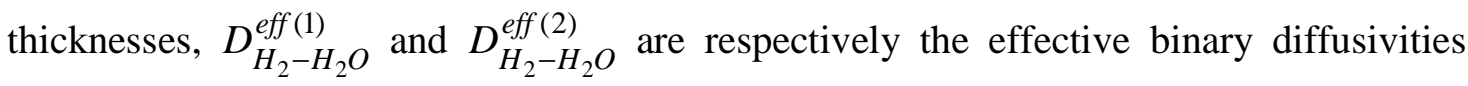
through the anode support and the anode functional layer. 
The effective diffusivities of mixed gases have been measured using techniques such as gas chromatography, steady-state diffusion cells, thermogravimetry using a microbalance, etc. However, measurements of effective diffusivities by these methods are typically conducted at one atmosphere pressure and over a temperature range from 30 to $300^{\circ} \mathrm{C}$. In order to measure the effective binary diffusivity of $\mathrm{O}_{2}-\mathrm{N}_{2}$ through porous media at the typical SOFC operating temperatures a special electrochemical concentration cell was fabricated by Zhao et al. [26]. Such a cell consists of a YSZ cylinder, a porous LSM disk attached to one side by a glass seal and a dense 8YSZ disc at the other end, also attached by a glass seal. A pair of porous platinum electrodes is applied on the YSZ disc and also across the YSZ cylinder wall. A DC voltage is applied across the YSZ disc with the platinum electrodes and the current flowing through the cell is measured. Oxygen can be pumped into or out of the chamber depending upon the polarity of the applied voltage. In steady state the net oxygen flux entering/leaving the chamber through the porous LSM disc is the same as the net oxygen flux leaving/entering the chamber through the YSZ disc. The oxygen partial pressure inside the chamber is measured using the pair of Pt electrodes applied across the YSZ cylinder wall which serves as a potentiometric sensor. From these measurements the effective binary diffusivity, $D_{O_{2}-N_{2}}^{e f f}$, through the porous LSM disk was measured as a function of porosity and temperature [26].

The $\mathrm{H}_{2}-\mathrm{H}_{2} \mathrm{O}$ effective binary diffusivity in porous anodes was measured by $\mathrm{He}$ et al.[27] using a similar electrochemical cell as used in the $\mathrm{O}_{2}-\mathrm{N}_{2}$ effective diffusivity 
measurements. In both studies the Nernst potential on the oxygen sensor was continuously measured until the oxygen partial pressure inside the chamber did not appreciably change with time. For the $\mathrm{H}_{2}-\mathrm{H}_{2} \mathrm{O}$ effective diffusivity measurements also the temperature was varied between 650 and $800^{\circ} \mathrm{C}$ in a 50 degree interval.

In order to obtain effective diffusivities at other temperatures the following approach is used in the present work. For an A-B binary system the effective diffusivity, $D_{A-B}^{e f f}$, is related to the A-B binary bulk diffusivity, $D_{A-B}$, through the phenomenological theory by [28]

$$
D_{A-B}^{e f f}=\frac{V_{v}}{\tau} D_{A-B}
$$

where $V_{v}$ is the volume fraction of porosity and $\tau$ is the tortuosity factor. The $D_{A-B}$ at moderate temperatures and pressures can be estimated by the Chapman-Enskog relation [28]

$$
D_{A-B}=\frac{0.00186 T^{\frac{3}{2}}\left(\frac{1}{M_{A}+M_{B}}\right)^{\frac{1}{2}}}{p \sigma_{A-B}^{2} \Omega}
$$

where $p$ is the pressure, $M_{A}$ and $M_{B}$ are the molecular weights of the two gaseous species and $\Omega$ is the collision integral, a dimensionless quantity which accounts for the interaction between the two species via the Lennard-Jones potential. The $\sigma_{A-B}$ is the 
collision diameter which is the arithmetic average of the diameters of the two gas species. Both $\mathrm{O}_{2}-\mathrm{N}_{2}$ and $\mathrm{H}_{2}-\mathrm{H}_{2} \mathrm{O}$ binary diffusivities can be found in [28].

Combining equations (20) with (21) gives

$$
D_{A-B}^{e f f}=k_{p} T^{\frac{3}{2}}
$$

where $k_{p}=\frac{V_{v}}{\tau} \frac{0.00186\left(\frac{1}{M_{A}+M_{B}}\right)^{\frac{1}{2}}}{p \sigma_{A-B}^{2} \Omega}$ is a constant corresponding to the porosity and the tortuosity of a given porous medium and the total pressure. By substituting for the measured $\mathrm{O}_{2}-\mathrm{N}_{2}$ and $\mathrm{H}_{2}-\mathrm{H}_{2} \mathrm{O}$ effective diffusivities at a given temperature into equation (22) the $k_{p}$ was estimated. In the work of Zhao et al. [26], the measured values of $D_{O_{2}-N_{2}}^{e f f}$ using an electrochemical cell at $800^{\circ} \mathrm{C}$ were $0.028 \mathrm{~cm}^{2} \mathrm{~s}^{-1}$ corresponding to porosity of $24.4 \%$ and $0.117 \mathrm{~cm}^{2} \mathrm{~s}^{-1}$ corresponding to porosity of $43.8 \%$. In the work of Zhao and Virkar [13], the fitted values of $D_{O_{2}-N_{2}}^{\text {eff }}$ at $800^{\circ} \mathrm{C}$ were $0.04 \mathrm{~cm}^{2} \mathrm{~s}^{-1}$ corresponding to porosity of $26 \%$ and $0.14 \mathrm{~cm}^{2} \mathrm{~s}^{-1}$ corresponding to porosity of $45 \%$. Thus the values measured on porous sample using an electrochemical cell [26] are essentially the same as fitted values in [13]. In our calculations the sets of values for $D_{O_{2}-N_{2}}^{e f f(1)}$ and $D_{O_{2}-N_{2}}^{e f f(2)}$ at $800^{\circ} \mathrm{C}$ used were respectively, $0.14 \mathrm{~cm}^{2} \mathrm{~s}^{-1}$ ( 45\% porosity) and $0.04 \mathrm{~cm}^{2} \mathrm{~s}^{-1}$ ( $26 \%$ porosity) obtained from the work of Zhao and Virkar [13]. Thus the 
values of $D_{\mathrm{H}_{2}-\mathrm{H}_{2} \mathrm{O}}^{\text {eff }(1)}$ and $D_{\mathrm{H}_{2}-\mathrm{H}_{2} \mathrm{O}}^{\text {eff }(2)}$ at $800^{\circ} \mathrm{C}$ used are respectively $0.68 \mathrm{~cm}^{2} \mathrm{~s}^{-1}(\sim 48 \%$ porosity) and $0.08 \mathrm{~cm}^{2} \mathrm{~s}^{-1}(\sim 23 \%$ porosity) obtained from the work Zhao and Virkar [13]. He et al [27] conducted measurement of $D_{\mathrm{H}_{2}-\mathrm{H}_{2} \mathrm{O}}^{\text {eff }}$ at $800^{\circ} \mathrm{C}$ using an electrochemical cell on a sample of $\mathrm{Ni}+\mathrm{YSZ}$ of $22 \%$ porosity. The measured value of $\mathrm{D}_{\mathrm{H}_{2}-\mathrm{H}_{2} \mathrm{O}}^{\text {eff }}$ was 0.07 $\mathrm{cm}^{2} \mathrm{~s}^{-1}$, which is close to the fitted value of $0.08 \mathrm{~cm}^{2} \mathrm{~s}^{-1}$ for a sample of $23 \%$ porosity in the work of Zhao and Virkar [13]. Thus, for the present calculations the values of $D_{\mathrm{H}_{2}-\mathrm{H}_{2} \mathrm{O}}^{\text {eff }(1)}$ and $\mathrm{D}_{\mathrm{H}_{2}-\mathrm{H}_{2} \mathrm{O}}^{\text {eff (2) }}$ reported by Zhao and Virkar [13] are used. Using these values the corresponding $k_{p}$ was calculated to be $3.98 \times 10^{-6}$ for $D_{O_{2}-N_{2}}^{e f f(1)}, 1.14 \times 10^{-6} D_{O_{2}-N_{2}}^{e f f(2)}$, $1.93 \times 10^{-5}$ for $D_{\mathrm{H}_{2}-\mathrm{H}_{2} \mathrm{O}}^{\text {eff }(1)}$ and $2.28 \times 10^{-6}$ for $D_{\mathrm{H}_{2}-\mathrm{H}_{2} \mathrm{O}}^{\text {eff }(2)}$, all in $\mathrm{cm}^{2} \mathrm{~s}^{-1} \mathrm{~K}^{-3 / 2}$. Using equation (22) $D_{A-B}^{e f f}$ for both the cathode and the anode were estimated at lower temperatures. The overall approach to the calculation of concentration polarization based on effective diffusivity measurements made on porous bodies is shown schematically in Figure 3. Figure 4 shows a schematic of a five layer cell and the variation of partial pressures of $\mathrm{H}_{2}, \mathrm{H}_{2} \mathrm{O}$ and $\mathrm{O}_{2}$ through respectively the anode and the cathode.

Activation Polarization: Activation polarizations at the two electrodes should strictly be described separately using parameters such as the exchange current densities and the transfer coefficients separately for the cathode and the anode. The difficulty has been in conducting accurate polarization measurements on actual cells and separating the cathode and the anode contributions. Measurements made using out-of-cell, the so-called threeelectrode system under an applied DC bias, are often inaccurate and not representative of 
the true SOFC operating conditions $[1,29]$. The principal problem is that the use of the out-of-cell three electrode system requires the application of an external voltage across the working and the counter electrodes. In the actual cell, however, there is no applied voltage - but a Nernst voltage is generated under the application of a difference in chemical potentials across the two electrodes. The spatial distributions of chemical potentials through the electrolyte are very different in the two situations. As such the measured electrode kinetics (such as the oxygen reduction reaction) under an applied voltage can be quite different than under an internally generated Nernst voltage [29].

An alternative is to measure the charge transfer characteristics using the three-electrode system under no applied DC bias using electrodes of well-defined geometries; e.g. welldefined three phase boundary (TPB) length, $\ell_{T P B}$, on a planar (2 dimensional) surface. Such a measurement can give the exchange current density as a function of test conditions (temperature and atmosphere) for the given electrode geometry, e.g. $\ell_{T P B}$. The exchange current densities at the cathode and the anode are dependent on both temperature and the partial pressure of the electroactive gaseous species in addition to $\ell_{T P B}$. A parameter which may be defined as charge transfer resistivity, $\rho_{c t}$, for the oxygen reduction reaction (ORR) has been measured on LSM/YSZ and Pt/YSZ electrode systems using patterned electrodes deposited by micro photolithography [30,31]. This parameter, $\rho_{c t}$, embodies the kinetics of the overall electrochemical reaction which depends upon a number of parameters such as the oxygen partial pressure, the temperature, the electronic and the ionic conductivities of the electrode and the electrolyte, adsorption, dissociation, electron transfer, etc. However, the $\rho_{c t}$ is 
independent of geometry, that is independent of $\ell_{T P B}$. The knowledge of $\rho_{c t}$ facilitates the estimation of the exchange current density for an actual three dimensional cathode provided the details of geometrical (microstructural) features are known.

For a composite electrode with a functional layer thickness greater than the threshold thickness the effective charge transfer resistance or the activation polarization resistance is given by [32]

$$
R_{c t}^{e f f} \approx \sqrt{\frac{d \rho_{i} \rho_{c t}}{\left(1-V_{v}\right) \ell_{T P B}}}=\frac{R T}{4 F i_{o}^{e f f}}
$$

where $\rho_{i}$ is the ionic resistivity of the composite electrode (that of YSZ in the electrode, for example), $d$ is the grain size of the composite electrode (that of YSZ in the electrode), $V_{v}$ is the volume fraction porosity, $\ell_{T P B}$ is the three phase boundary (TPB) length in the composite electrode (distributed on the surface of a three dimensional porous structure), $i_{o}^{e f f}$ is the effective exchange current density of the composite electrode which takes into account the distributed electrochemical reaction through the thickness of the electrode and $\rho_{c t}$ is the charge transfer resistivity, a fundamental, microstructure-independent parameter which describes the resistance to the overall charge transfer reaction [26]. The $\rho_{c t}$ is a measure of the kinetics of the overall intrinsic electrode reaction, namely $1 /{ }_{2} \mathrm{O}_{2}$ (gas) $+2 \mathrm{e}^{\prime}$ (electrocatalyst, e.g. LSM) $\rightarrow \mathrm{O}^{2-}$ (electrolyte, e.g. YSZ). There are a number of series steps in this reaction such as: (a) adsorption of $\mathrm{O}_{2}$, (b) dissociation of the adsorbed $\mathrm{O}_{2}$ into adsorbed 2O, (c) electron transfer to form $\mathrm{O}^{2-}$ and (d) its incorporation into the electrolyte which typically involves a vacancy mechanism. At the present no experimental or theoretical methods are known 
that can unequivocally determine each of the steps quantitatively and provide independent verification. However, the $\rho_{c t}$ measured by patterned electrodes includes the effects of all of these steps. This is the parameter which can be measured and thus constitutes as one of the input parameters in our model.

For cathode activation polarization it was shown that $\rho_{c t(c)}\left(T, p_{\mathrm{O}_{2}}\right)$ is of the form [30, 31]

$$
\rho_{c t(c)}\left(T, p_{O_{2}}\right) \approx \rho_{c t(c)}^{\prime \prime}(T)+\frac{\rho_{c t(c)}^{\prime \prime}(T)}{b_{c}^{*}(T) \sqrt{p_{O_{2}}}}
$$

where $b_{c}^{*}(T)$ is the Langmuir adsorption coefficient and $\rho_{c t(c)}^{\prime \prime}(T)$ is the charge transfer resistivity corresponding to an adsorbed oxygen surface coverage of unity. The $\rho_{c t(c)}\left(T, p_{O_{2}}\right)$ is a measure of the overall charge transfer reaction and involves a number of series steps.

Substitution of the above parameters for a composite cathode into equation (25) gives [32]

$$
i_{o(c)}^{e f f} \approx \frac{R T}{4 F} \sqrt{\frac{\left(1-V_{v(c)}\right)}{\rho_{i} d_{c}}} \sqrt{\frac{\ell_{T P B(c)}}{\rho_{c t(c)}\left(T, p_{O_{2}}\right)}}
$$

which is the effective exchange current density for the composite, three dimensional cathode given as a function of temperature and oxygen partial pressure in terms of measurable parameters (namely, $V_{v(c)}, d_{c}, \ell_{T P B(c)}, \rho_{i}$, and $\rho_{c t(c)}$ ) where subscript 'c' denotes cathode parameters. The preceding assumes dissociative adsorption of $\mathrm{O}_{2}$. 
To calculate the cathode activation polarization the experimentally measured charge transfer resistivities, $\rho_{c t(c)}\left(T, p_{O_{2}}\right)$, using patterned electrodes are available for LSM/YSZ and Pt/YSZ systems [30,31]. In those studies $\rho_{c t(c)}^{\prime \prime}(T)$ and $b_{c}^{*}(T)$ in equation (24) for LSM/YSZ and Pt/YSZ were measured over a temperature range from 650 to $800^{\circ} \mathrm{C}$ in 50 degree intervals. Since $\rho_{c t(c)}^{\prime \prime}(T)$ is thermally activated, it is of the form

$$
\rho_{c t(c)}^{\prime \prime}(T)=\rho_{c t(c)_{o}}^{\prime \prime} \exp \left[\frac{Q_{c}}{R T}\right]
$$

where $\rho_{c t(c)_{o}}^{\prime \prime}$ is a constant and $Q_{c}$ is the activation energy. A plot of $\ln \left(\rho_{c t(c)}^{\prime \prime}(T)\right)$ vs. 1/T is expected to be linear with slope given by $\frac{Q_{c}}{R}$ and intercept given by $\ln \left(\rho_{c t(c)_{o}}^{\prime \prime}\right)$. Using the data given in $[30,31]$ and the plots of $\ln \left(\rho_{c t(c)}^{\prime \prime}(T)\right)$ vs $1 / T$ the activation energies of $\rho_{c t(c)}^{\prime \prime}(T)$ for LSM/YSZ and Pt/YSZ cathodes were estimated as $\sim 143$ and $\sim 159 \mathrm{kJmol}^{-1}$, respectively. The pre-exponential constants $\rho_{c t(c)_{o}}^{\prime \prime}$ for LSM/YSZ and Pt/YSZ cathodes are $7.71 \times 10^{-3}$ and $5.94 \times 10^{-5} \Omega \mathrm{cm}$, respectively. The plot of $\ln \left(b_{c}^{*}(T)\right)$ vs. $1 / \mathrm{T}$ does not follow a linear behavior. However, a plot of $b_{c}^{*}(T)$ as a function of $1 / T$ is found to be linear, i.e.,

$$
b_{c}^{*}(T)=\frac{a_{c}}{T}+b_{c}
$$

The slopes are $-1.12 \times 10^{3} \mathrm{~atm}^{-1 / 2} \mathrm{~K}$ for $\mathrm{LSM} / \mathrm{YSZ}$ and $1.05 \times 10^{5} \mathrm{~atm}^{-1 / 2} \mathrm{~K}$ for $\mathrm{Pt} / \mathrm{YSZ}$, respectively. The intercepts, $b_{c}$, are 4.25 and $-94.79 \mathrm{~atm}^{-1 / 2}$, respectively, for LSM/YSZ and Pt/YSZ. Note that these are empirical fits. Thus, the observation that in 
one case $b_{c}$ is negative has no specific meaning. What is important to note is that over the range of temperatures that equation (27) is used, the value of the Langmuir adsorption coefficient, $b_{c}^{*}(T)$, is always positive as required.

In equation (25) for the exchange current density at the cathode it is understood that the partial pressure of the active species (oxygen) is that close to the functional layer/electrolyte interface; that is $p_{O_{2}}^{\prime}(i)$. This partial pressure is a function of the porosities, the tortuosities, the thicknesses of the porous layers, the partial pressure of the oxidant in the incoming gas and the net current density, $i$. That is, $i_{o(c)}^{e f f}$ is also affected by concentration polarization. Thus, it is first necessary to estimate $p_{\mathrm{O}_{2}}^{\prime}(i)$ which is dictated by concentration polarization governed by the net current density, $i$, which is the independent variable in the model. For an arbitrarily chosen $i$, the $p_{O_{2}}^{\prime}(i)$ is estimated from equation (16). Using this value of $p_{O_{2}}^{\prime}(i)$, the $\rho_{c t(c)}\left(T, p^{\prime} O_{2}(i)\right)$ is estimated using equation (24) and from equation (25) the $i_{o(c)}^{e f f}$ is estimated. Finally using the estimated value of $i_{o(c)}^{e f f}$, which is a function of $i$, the cathode activation polarization is calculated as discussed later.

Thus, as discussed in the preceding, combining equations (23), (24) and (26), the charge transfer resistivity, $\rho_{c t(c)}\left(T, p^{\prime} O_{2}(i)\right)$, can be estimated as a function of temperature and $p^{\prime} O_{2}(i)$ which is used to estimate the effective exchange current density. 
In the present work calculations of $i_{o(c)}^{e f f}$ are conducted for three different microstructures in the cathode functional layer: $d_{c}=2 \mu \mathrm{m}, d_{c}=0.2 \mu \mathrm{m}$, and $d_{c}=0.02 \mu \mathrm{m}$. The first is routinely achieved using typical ceramic powders. The second one can be achieved using processes that can form nanometer scale powders at low temperatures. The third type of microstructure may be obtained by nanometer scale powders and low temperature processing. Corresponding to the three microstructures the three values of the three phase boundary lengths, $\ell_{T P B}$, used are: $\ell_{T P B}=10,000 \mathrm{~cm}^{-1}, \ell_{T P B}=100,000 \mathrm{~cm}^{-1}$ and $\ell_{T P B}=$ $1,000,000 \mathrm{~cm}^{-1}$. These correspond to $50 \%$ surface coverage of the porous electrode interior surface by the electrocatalyst (LSM or Pt) particles of a size equal to $d_{c} / 2$. The functional layer thickness was assumed to be $15 d_{c}$ based on the prior modeling work [32]. The experimental work on microstructural features on the order of a few microns has shown that these estimates are very reasonable [33].

For anode activation polarization similar equations are given in what follows. In the case of the anode it is expected that the partial pressure dependence of the charge transfer resistivity is on $p_{\mathrm{H}_{2}}$. Thus, for the anode one may write

$$
i_{o(a)}^{e f f} \approx \frac{R T}{4 F} \sqrt{\frac{\left(1-V_{v(a)}\right)}{\rho_{i} d_{a}}} \sqrt{\frac{\ell_{T P B(a)}}{\rho_{c t(a)}\left(T, p_{H_{2}}\right)}}
$$

where

$$
\rho_{c t(a)}\left(T, p_{H_{2}}\right) \approx \rho_{c t(a)}^{\prime \prime}(T)+\frac{\rho_{c t(a)}^{\prime \prime}(T)}{b_{a}^{*}(T) \sqrt{p_{H_{2}}}}
$$


The subscript ' $a$ ' denotes anode parameters. The preceding assumes that the electrochemical reaction involves one mole of $\mathrm{O}_{2}$ and 2 moles of $\mathrm{H}_{2}$. Also the preceding assumes dissociative adsorption of $\mathrm{H}_{2}$.

Once again in order to study the anode activation polarization one of the challenges is to determine the relationship between the length of TPB and the charge-transfer resistance in an actual electrode in order to determine the charge transfer resistivity, a microstructure-independent parameter. This is difficult to achieve using a conventional porous composite electrode and measurements on well-defined Ni/YSZ patterned electrodes are necessary. A few studies have reported on the charge transfer reaction mechanism for electrochemical oxidation of hydrogen in SOFC using Ni/YSZ patterned anodes $[34,35]$. While these studies provided detailed discussions on the hydrogen oxidation mechanisms, direct relationship such as equation (29) between the charge transfer resistivity and hydrogen partial pressure, which is needed to estimate anode activation polarization, was not given. However, based on the reported data on Ni/YSZ patterned anodes [34], it is possible to plot $\rho_{c t(a)}\left(T, p_{H_{2}}\right)$ as a function of $1 / \sqrt{p_{H_{2}}}$ at various temperatures using the methods described in [30,31] and to fit the data to an equation similar to (26). Figure 5 shows similar plots of data given by Bieberle et al [34]. As seen in Figure 5 such plots are linear with slope $=\frac{\rho_{c t(a)}^{\prime \prime}(T)}{b_{a}^{*}(T)}$ and intercept $=\rho_{c t(a)}^{\prime \prime}(T)$.

Since $\rho_{c t(a)}^{\prime \prime}(T)$ is also thermally activated it follows a similar equation as used for the cathode charge transfer resistivity, namely 


$$
\rho_{c t(a)}^{\prime \prime}(T)=\rho_{c t(a)_{o}}^{\prime \prime} \exp \left[\frac{Q_{a}}{R T}\right]
$$

where $\rho_{c t(a)_{o}}^{\prime \prime}$ is a constant and $Q_{a}$ is the activation energy. A plot of $\ln \rho_{c t(a)}^{\prime \prime}(T)$ vs $1 / T$ thus should be linear with slope given by $\frac{Q_{a}}{R}$ and intercept given by $\ln \left(\rho_{c t(a)_{o}}^{\prime \prime}\right)$. Using the data given in [34] and plotting $\ln \rho_{c t(a)}^{\prime \prime}(T)$ vs $1 / T$, the activation energy of $\rho_{c t(a)}^{\prime \prime}(T)$ for Ni/YSZ anode is determined to be $85 \mathrm{kJmol}^{-1}$. The pre-exponential constant $\rho_{\operatorname{ct}(a)_{o}}$ is $2.72 \Omega \mathrm{cm}$. The plot also shows that $b_{a}^{*}(T)$ is nearly a constant independent of temperature with a value of about $6.3 \mathrm{~atm}^{-1 / 2}$.

For the estimation of the effective anode exchange current density, $i_{o(a)}^{e f f}$, three different types of microstructures, namely $d_{a}=2 \mu \mathrm{m}, d_{a}=0.2 \mu \mathrm{m}$ and $d_{a}=0.02 \mu \mathrm{m}$ were used, the same as for the cathode functional layer. The corresponding three phase boundary lengths are $10,000 \mathrm{~cm}^{-1}, 100,000 \mathrm{~cm}^{-1}$ and $1,000,000 \mathrm{~cm}^{-1}$. The procedure for the calculation of $i_{o(a)}^{e f f}$ is similar to that of $i_{o(c)}^{e f f}$. For given values of partial pressures of hydrogen, $p_{\mathrm{H}_{2}}^{o}$, and water vapor, $p_{\mathrm{H}_{2} \mathrm{O}}^{o}$, in the anode gas and for an arbitrarily selected net current density, $i$, the $p_{H_{2}}^{\prime}(i)$ is estimated using equation (18). Then from equation (29) the corresponding charge transfer resistivity is calculated using equation (30), namely, $\rho_{c t(a)}\left(T, p^{\prime} H_{2}(i)\right) \approx \rho_{c t(a)}^{\prime \prime}(T)+\frac{\rho_{c t(a)}^{\prime \prime}(T)}{b_{a}^{*}(T) \sqrt{p^{\prime} H_{2}(i)}}$, which is a function of the net current density, $i$. From this calculation using equation (28) the effective exchange 
current density, $i_{o(a)}^{e f f} \approx \frac{R T}{4 F} \sqrt{\frac{\left(1-V_{v(a)}\right)}{\rho_{i} d_{a}}} \sqrt{\frac{\ell_{T P B(a)}}{\rho_{c t(a)}\left(T, p^{\prime} H_{2}(i)\right)}}$, is estimated. Note that this is a function of the net current density.

The Tafel equation may be used to describe the dependence of activation polarization on current density for values of current density well above the effective exchange current density. For current densities lower than the effective exchange current density, $i_{o}^{\text {eff }}$, it is necessary to either simplify the Butler-Volmer equation and use a linear relationship or alternatively use the complete Butler-Volmer equation. In a typical SOFC at elevated temperatures effective exchange current densities can be quite high - several tens or even hundreds of $\mathrm{mAcm}^{-2}$. For example for an $R_{c t(c)}^{\text {eff }}$ of $0.05 \Omega \mathrm{cm}^{2}$, a value that has been reported on a number of highly active cathodes at $800^{\circ} \mathrm{C}$, the corresponding cathode exchange effective current density, $i_{o(c)}^{e f f}$, is $\sim 460 \mathrm{mAcm}^{-2}$. Thus, the use of the ButlerVolmer equation may be necessary especially at lower current densities and the Tafel equation can only be used at much higher current densities. Either approach, however, requires the knowledge of the transfer coefficient. In the absence of information on the transfer coefficient in what follows we assume a transfer coefficient of 0.5 which also facilitates writing an analytical equation for the activation polarization in terms of the current density (instead of using the Butler -Volmer equation with transfer coefficient different from 0.5 in which the current density is an implicit function of the overpotential). 
Finally once the effective exchange current densities at both the anode and the cathode are known, the activation polarization at the two electrodes can be calculated separately. For the cathode the activation polarization may be given by

$$
\eta_{a c t}^{c}=\frac{R T}{2 F} \arcsin \mathrm{h}\left(\frac{i}{2 i_{o(c)}^{e f f}}\right)
$$

where we have assumed the transfer coefficient to be 0.5. Similarly, the activation polarization for the anode is given by

$$
\eta_{a c t}^{a}=\frac{R T}{2 F} \arcsin \mathrm{h}\left(\frac{i}{2 i_{o(a)}^{e f f}}\right)
$$

with once again transfer coefficient assumed as 0.5. At present there does not appear to be a reliable method for measuring the transfer coefficient as this requires an experimental measurement of both activation polarizations at the anode and cathode separately on an actual cell and as functions of current density. The overall approach used here for the determination of activation polarization, based on charge transfer resistivity measurements made on patterned electrodes, is shown in Figure 6.

\section{Procedure for Calculations:}

Figure 4 shows a schematic of a five layer cell used for calculations in the present work [13]. Values of $p_{\mathrm{H}_{2}}^{o}, p_{\mathrm{H}_{2} \mathrm{O}}^{o}$ (fuel) and $p_{\mathrm{O}_{2}}^{o}$ (oxidant) are selected corresponding to the typical operating conditions. For example for the incoming fuel the $p_{\mathrm{H}_{2}}^{o}$ is $\sim 0.97 \mathrm{~atm}$ and for the incoming oxidant the $p_{\mathrm{O}_{2}}^{o}$ is $\sim 0.21$ atm. Calculations can be readily made for depleted fuel and oxidant and will represent local performance corresponding to given 
local fuel and oxidant utilizations. A set of effective diffusivities for the anode and the cathode are used based on measurements as described earlier. The cell ohmic ASR is estimated from the knowledge of the respective resistivities of the layers and the estimated contact resistances as described earlier.

The independent variable in the calculations is the net current density, $i$. All polarization losses are calculated for any given value of the current density. The corresponding cell voltage, $V(i)$, is given by the Nernst voltage minus all of the various polarizations (equation (1)). The short circuit current density is the one for which the $V(i)$ is zero.

For a given current density the ohmic loss is the product of the current density and the ohmic ASR.

For a given current density the partial pressures of hydrogen, $p_{H_{2}}^{\prime}(i)$, and water vapor, $p_{\left.\mathrm{H}_{2} \mathrm{O}\right)}^{\prime}(i)$, near the anode functional layer/electrolyte interface and the partial pressure of oxygen, $p_{\mathrm{O}_{2}}^{\prime}(i)$, near the cathode functional layer/electrolyte interface were determined (using equations (16), (18) and (19)). This allowed for the estimation of the respective concentration polarizations.

Using the estimated partial pressures close to the electrolyte/electrode functional layer interfaces, the corresponding charge transfer resistivities were estimated using charge transfer resistivities measured by patterned electrodes [30, 31, 34]. For example for the cathode the relevant equation is (24). The effective charge transfer resistance (or 
exchange current density) was estimated (equations (23), (24), and (25)). The calculations were made for various microstructures for the functional layer; namely the grain size, $d$, volume fraction porosity, $V_{v}$, and the three phase boundary length, $\ell_{T P B}$. The values selected for the following calculations are those that are deemed experimentally realistic. For the cathode, calculations are made at a given temperature for a wide range of oxygen partial pressures, $p_{\mathrm{O}_{2}}$. This effectively is a calculation corresponding to a given $p_{\mathrm{O}_{2}}^{\prime}$, the oxygen partial pressure close to the cathode functional layer/electrolyte interface. Depending upon the details of the electrode and the oxygen partial pressure in the oxidant, $p_{\mathrm{O}_{2}}^{o}$, a given $p_{\mathrm{O}_{2}}^{\prime}$ is achieved at some value of the operating current density, $i$. The effective exchange current density is a function of temperature, $T$, and oxygen partial pressure, $p_{\mathrm{O}_{2}}^{\prime}$, namely $i_{o(c)}^{e f f}\left(T, p_{\mathrm{O}_{2}}^{\prime}\right)$. Once this is obtained the activation polarization at the cathode, $\eta_{a c t}^{c}(i)$, is estimated using equation (31). This allows for the estimation of $\eta_{a c t}^{c}(i, T)$ as a function of temperature and current density since a given $p_{\mathrm{O}_{2}}^{\prime}$ (which is a function of current density $i, p_{\mathrm{O}_{2}}^{\prime}(i)$ ) is attained at a given current density which depends on details of the electrode (microstructure and thickness). Similar calculations are made for the anode activation polarization using equations (28), (29), (30) and (32). In this manner all polarization contributions were determined as a function of current density, $i$. Figure 7 shows a flow diagram of the procedure used for calculations. 
Figure 8(a) and Figure 8(b) are respectively the calculated values of the partial pressure of hydrogen, $p_{H_{2}}^{\prime}(i)$, in the anode functional layer close to the electrolyte and oxygen partial pressure, $p_{\mathrm{O}_{2}}^{\prime}(i)$, in the cathode functional layer close to the electrolyte as a function of the net current density, $i$. As the current density increases the interface partial pressures decrease to maintain the corresponding gaseous fluxes. The lowest values of the interface partial pressures approach zero (but do not exactly become zero to ensure gas phase equilibria are maintained). The decrease in partial pressures at the interfaces affects the local charge transfer resistivities given by equation (24) at the cathode and by equation (29) at the anode. As a result, the effective exchange current density at the cathode, $i_{o(c)}^{e f f}$, given by equation (25) and the effective exchange current density at the anode, $i_{o(a)}^{e f f}$, given by equation (28) are also affected. Figure 9(a) shows the calculated $i_{o(a)}^{e f f}$ as a function of current density and Figure 9(b) shows the calculated $i_{o(c)}^{e f f}$ as a function of current density for electrode grain size of $2 \mu \mathrm{m}$. As seen in the figures as the current density increases the effective exchange current densities decrease. Finally Figure 10(a) and Figure 10(b) respectively show the calculated activation polarization at the anode, $\eta_{a c t}^{a}$, as a function of current density and activation polarization at the cathode, $\eta_{a c t}^{c}$, as a function of current density. The very sharp increases in activation polarizations at high current densities are the result of local depletion of oxygen at the cathode 
functional layer/electrolyte interface and local depletion of hydrogen at the anode functional layer/electrolyte interface.

Figure 11(a) shows the calculated polarizations at $800^{\circ} \mathrm{C}$ for an anode-supported cell with an $8 \mu \mathrm{m}$ thick YSZ electrolyte, $\mathrm{Ni}+\mathrm{YSZ}$ anode support of thickness $1 \mathrm{~mm}$, cathode LSM current collector of thickness $50 \mu \mathrm{m}$ and YSZ grain size in the functional layers of $2 \mu \mathrm{m}$. The thicknesses of both the cathode and anode functional layers in each calculation were $15 \mathrm{~d}$. Thus, in this calculation the cathode and anode functional layer thicknesses were $30 \mu \mathrm{m}$ each. The ohmic ASR was assumed to be $0.1 \Omega \mathrm{cm}^{2}$ a value measured at $800^{\circ} \mathrm{C}$ in previous work [13]. At low current densities the dominant polarization losses are activation polarization losses at both the cathode and the anode. At higher current densities the ohmic loss dominates even with a thin YSZ film electrolyte. The concentration polarization at the cathode is rather small but that at the anode is substantial as the anode support thickness is relatively large $-1 \mathrm{~mm}$. The corresponding voltage vs. current density and power density vs. current density plots are given in Figure 11(b). It is seen that the initial part of the $V(i)$ vs. $i$ curve shows a concave up curvature typical of activation polarization at low current densities. Part of the concave nature of the voltage vs. current density curves is also attributed to anode concentration polarization [3]. The maximum power density calculated is $\sim 1.0 \mathrm{Wcm}^{-2}$ a typical value reported in a number of studies, especially with relatively coarse electrode microstructures. 
Figure 12(a) shows similar calculations of polarizations for a cell with electrode grain size of $0.2 \mu \mathrm{m}$. Thus, the corresponding functional layer thicknesses are $3 \mu \mathrm{m}$. All other parameters are the same as in Figure 11(a). Now it is seen that both activation and cathode concentration polarization losses are much lower than the ohmic loss over the entire range of current densities. The anode concentration polarization loss is substantial, attributed to its large $(1 \mathrm{~mm})$ thickness. Figure 12(b) shows the corresponding voltage vs. current density and power density vs. current density plots. The $V(i)$ vs. $i$ plot shows very little concave up curvature, since even at the lowest values of the current density the ohmic loss dominates. The maximum power density is about $1.8 \mathrm{Wcm}^{-2}$. Many studies have reported similar power densities especially when the electrode microstructures are relatively fine. Figure 12(a) and Figure 12(b) thus suggest that further improvement in electrode may not substantially increase performance.

Figures 13(a) and 13(b) show similar calculations but now with electrode grain size of $0.02 \mu \mathrm{m}$. Such a fine electrode microstructure may be possible by low temperature processing. The activation polarization losses are even smaller and the ohmic loss continues to dominate. The voltage vs. current density plot is almost linear. The maximum power density is now higher $\left(\sim 2.2 \mathrm{Wcm}^{-2}\right)$. But it is clear that further increase in performance can be realized only through lowering of the ohmic loss and by decreasing the anode concentration polarization. The anode polarization can be decreased by increasing the anode support porosity, decreasing the anode support thickness or both. Zhao and Virkar [13] observed significantly higher performance on cells made with 
anode support containing $57 \%$ as compared cells made with $48 \%$ and lower porosity. In what follows, we examine the effect of anode support thickness.

Figure 14(a) and Figure 14(b) show plots of polarization vs. current density and voltage and power density vs. current density for cells with anode support thickness of $0.5 \mathrm{~mm}$ and electrode grain sizes of $0.02 \mu \mathrm{m}$. Comparison with Figure 13 shows substantially lower anode concentration polarization and higher cell performance. Self-supporting cells with anode support thickness of $\sim 0.5 \mathrm{~mm}$ can be routinely made.

Figure 15(a) and Figure 15(b) show plots of polarization vs. current density and voltage and power density vs. current density for cells with anode support thickness of $0.1 \mathrm{~mm}$ and electrode grain sizes of $0.02 \mu \mathrm{m}$. Comparison with Figure 14 shows substantially lower anode concentration polarization and higher cell performance. The most dominant loss is ohmic loss and underscores the importance of need to lower it in order to increase cell performance. While self-supporting cells with anode support thickness of $0.1 \mathrm{~mm}$ may be difficult (not robust enough), an additional support of a rugged highly porous metallic support is an option. Indeed, currently there are several efforts underway on metal supported SOFC.

Calculation of Performance Curves and Comparison with Experiments: Figure 16 compares experimentally measured voltage vs. current density and power density vs. current density data [13] with cell performance calculations made in this study using the 
parametric model and property measurements made on cell materials and cell components. An important point to note is that the calculations given in Figure 16 are based on measurements primarily made on cell materials and cell components and the parametric model and not fits to cell test data. Thus, this is a solution to the forward problem, unlike the commonly made measurements on cells using techniques such as EIS which cannot give unique values because of the inverse nature of the problem. At $800^{\circ} \mathrm{C}$ and $700^{\circ} \mathrm{C}$, the calculated performance curves are in good agreement with the experimentally measured values. At $600^{\circ} \mathrm{C}$, the agreement is good at low current densities (up to about $0.5 \mathrm{Acm}^{-2}$ ). Again an important point is that the cell performance curves are calculated using property measurements made on cell materials and cell components by appropriate selection of materials and microstructures, fundamental studies on charge transfer measurements. The present results thus also suggest that such an approach may help develop solid oxide fuel cells exhibiting good performance characteristics at low operating temperatures. In what follows we now examine how one may develop solid oxide fuel cells with high performance using values of parameters measured on cell materials and cell components, and using the parametric model described here.

\section{Effect of Temperature on Performance of Cells with YSZ and GDC Electrolytes: Figure} 17 and Figure 18 show the calculated performance curves for cells with $8 \mu \mathrm{m} \mathrm{YSZ}$ electrolyte and electrode grain sizes of $2 \mu \mathrm{m}$ and $0.2 \mu \mathrm{m}$, respectively, over a range of temperatures from $500^{\circ} \mathrm{C}$ and $800^{\circ} \mathrm{C}$. The ohmic area specific resistance was calculated at each temperature using the equations given in Table 2. The contact resistance was assumed to be equal to the calculated ohmic area specific resistance (that is the contact 
resistance is $50 \%$ of the total ohmic resistance). Literature search shows that in many reported studies the ohmic contribution is much larger than can be accounted for based on individual component resistances suggesting that in many cells there is a significant contribution to the ohmic resistance from interlayer contacts. As seen from Figures 17 and 18 , at $800^{\circ} \mathrm{C}$ the cell with $0.2 \mu \mathrm{m}$ electrode grain size exhibits much higher performance than the cell with $2 \mu \mathrm{m}$ electrode grain size. This is consistent with expectations since activation polarization contribution is significant in the cell with $2 \mu \mathrm{m}$ electrode grain size. At $500^{\circ} \mathrm{C}$, however, the most dominant contribution is from the ohmic loss and the cell performance is not much affected by the electrode microstructure (over the range of electrode microstructures selected here for calculations). As a result more active electrodes do not lead to a proportionate increase in performance.

Figures 19 and 20 are similar plots with GDC electrolyte of $8 \mu \mathrm{m}$ thickness. The contact resistance was again assumed to be equal to the total calculated ohmic resistance of the five layers. Also, cathode and anode were respectively LSM + YSZ and Ni + YSZ since fundamental measurements are available only for these two sets of materials. Note that the performance is much higher with GDC electrolyte at all temperatures. Also, at $500^{\circ} \mathrm{C}$ the performance is higher with $0.2 \mu \mathrm{m}$ electrode grain size compared to $2 \mu \mathrm{m}$ electrode grain size. The ohmic contribution is much lower. As a result, improvement in electrode microstructure leads to an increase in performance. In these calculations it was assumed that a very thin layer exhibiting a very high electronic resistance is deposited on the GDC electrolyte to block off the electronic leakage current. 
Contact resistance, associated with the possible existence of interface delaminations and cracks, as well as the formation of insulating phases such as $\mathrm{SrZrO}_{3}$ and $\mathrm{La}_{2} \mathrm{Zr}_{2} \mathrm{O}_{7}$ at electrolyte/electrode interfaces, was found to be a significant contributor to the overall ohmic resistance. This may be reduced by developing fabrication processes to ensure that cracks or delaminations do not occur. Also, by lowering electrode firing temperature or by introducing electrocatalysts by infiltration may suppress the formation of insulating phases. Also, the anode support thickness selected for most of the calculations was 1 $\mathrm{mm}$. The corresponding anode concentration polarization is substantial. Calculations also showed that when the anode support thickness is reduced to $0.5 \mathrm{~mm}$ and $0.1 \mathrm{~mm}$, the anode concentration polarization was substantially reduced.

The preceding shows that it should be possible to design cells exhibiting high performance at low to intermediate temperatures using LSM + YSZ cathode and Ni + YSZ anode of fine microstructures and with higher ionic conductivity electrolyte materials such as GDC or LSGM. The possible reaction of these different electrolytes with the electrodes can be minimized or prevented by depositing suitable barrier layers. In order to incorporate other electrodes and use the parametric model, it would be necessary to measure charge transfer reaction kinetics using patterned electrodes. Such data are available with $\mathrm{Pt}+\mathrm{YSZ}$ as the cathode [30]. Prior work has shown that Pt + YSZ is a more active cathode than LSM + YSZ. Thus we expect cells made with $\mathrm{Pt}+\mathrm{YSZ}$ as the cathode should exhibit higher performance. Indeed, it is well known that the introduction of Pt into the cathodes by infiltration leads to higher performing cathodes and thus higher performing cells. Although Pt is an expensive catalyst, a small amount 
added as an infiltrant into standard cathodes such as LSM + YSZ may be cost effective at least in some applications.

\section{SUMMARY}

A parametric model for anode-supported solid oxide fuel cells (SOFC) is presented to describe various polarizations, cell voltage and power density as functions of current density. All polarizations or voltage losses are calculated based on measurements made on cell materials and cell components. This included the measurement of effective gas phase diffusivities through prospective anode and cathode, charge transfer resistivities for oxygen reduction reaction at the cathode and hydrogen oxidation reaction at the anode using patterned electrodes and measurements of electrical resistivities of components cathode, anode and the electrolyte of appropriate materials and microstructures. Thus, what is presented here is not a model to fit experimental cell test data, but rather to generate cell performance curves based on property measurements made on cell materials and cell components, electrode microstructural measurements, gas phase transport properties measurements and fundamental measurements on cathode and anode electrocatalysis. The calculated performance curves are in good agreement with a number of reported cell test data. Since the model is based on parameters measured on cell materials and cell components, comparison of the model with actual cell test data 
provides an independent validation of the model. Also, the model thus provides guidelines for the design of high performance cells by judiciously selecting materials and microstructures for the various cell components.

One of the most important conclusions is that if sufficiently fine electrode microstructures can be achieved (electrode grain size of $\sim 0.5 \mu \mathrm{m}$ or smaller) with traditional electrodes ( $\mathrm{Ni}+$ YSZ for the anode, LSM + YSZ for the cathode), even in thin YSZ electrolyte $(\sim 8 \mu \mathrm{m})$ anode-supported cells at $800^{\circ} \mathrm{C}$, substantial voltage loss is associated with the ohmic contribution and not necessarily the polarization losses at the electrodes. At lower temperatures, the effect of the ohmic contribution becomes even larger. The observation that most YSZ electrolyte based anode-supported cells at $800^{\circ} \mathrm{C}$ exhibit a maximum power density of $\sim 2 \mathrm{Wcm}^{-2}$ despite using a variety of cathodes is consistent with the ohmic contribution being the dominant one. This conclusion assumes that the electrode microstructure is sufficiently fine.

Calculations made with a higher ionic conductivity material for the electrolyte (GDC) but with the same electrodes (Ni + YSZ and LSM + YSZ) show substantially higher performance than with YSZ as the electrolyte because of the much higher conductivity of GDC. Also, since much of the electrocatalysis at the cathode and the anode occurs within the functional layers (not at the electrolyte/functional layer interfaces), the present results suggest that with a given set of materials for the electrodes (for which fundamental information on electrocatalysis is available) any electrolyte which is physically, chemically and mechanically compatible with the electrodes can be used to improve the 
performance even further. For example, with the same electrodes, one may use LSGM thin film electrolyte. Naturally, additional thin barrier layers between the electrolyte and the electrodes may be necessary to ensure compatibility. Insofar as the electrodes are concerned, further work is needed to conduct studies using patterned electrodes to determine fundamental parameters such as the charge transfer resistivity of other prospective electrode material-electrolyte material combinations.

In the present work, most of the calculations were done for cells with an anode support thickness of $1 \mathrm{~mm}$ and anode support porosity of $48 \mathrm{vol} . \%$. The corresponding anode concentration polarization was substantial. It is readily seen that if the anode support thickness is lowered, a significant lowering of the anode concentration polarization occurs. Thus, when the electrodes are highly active (fine microstructures) and anode concentration polarization is lowered by decreasing anode support thickness and increasing anode porosity, the principal loss is attributed to the ohmic contribution.

\section{Acknowledgments}

This work was supported at the University of Utah by the US Department of Energy under Grant Number DE-FG02-06ER46086 (A. Virkar - modeling; L. Zhu - numerical analysis, Lei Zhang - numerical analysis) and the US Department of Energy EFRC Grant Number SC0001061 as a flow-through from the University of South Carolina (A. Virkar - modeling; L. Zhu - numerical analysis). 


\section{$\underline{\text { List of Symbols: }}$}

$a$ : Denotes anode parameters (subscript or superscript).

$b^{*}(T)$ : Langmuir adsorption coefficient $\left(\mathrm{atm}^{-1 / 2}\right)$

$c$ : Denotes cathode parameters (subscript or superscript).

$d$ : Grain size of composite electrode $(\mathrm{cm})$

$D_{O_{2}-N_{2}}^{\text {eff }(1)}$ : Effective binary diffusivity through the cathode current collector $\left(\mathrm{cm}^{2} \mathrm{~s}^{-1}\right)$

$D_{O_{2}-N_{2}}^{e f f(2)}$ : Effective binary diffusivity through the cathode functional layer $\left(\mathrm{cm}^{2} \mathrm{~s}^{-1}\right)$

$D_{\mathrm{H}_{2}-\mathrm{H}_{2} \mathrm{O}}^{\text {eff }(1)}$ : Effective binary diffusivity through the anode support $\left(\mathrm{cm}^{2} \mathrm{~s}^{-1}\right)$

$D_{\mathrm{H}_{2}-\mathrm{H}_{2} \mathrm{O}}^{\text {eff }}$ : Effective binary diffusivity through the anode functional layer $\left(\mathrm{cm}^{2} \mathrm{~s}^{-1}\right)$

$D_{A-B}:$ Binary A-B diffusivity $\left(\mathrm{cm}^{2} \mathrm{~s}^{-1}\right)$

$D_{A-B}^{e f f}:$ Effective diffusivity of A-B binary system $\left(\mathrm{cm}^{2} \mathrm{~s}^{-1}\right)$

$E_{o}:$ Open circuit voltage (V)

$F$ : Faraday constant $\left(\mathrm{Cmol}^{-1}\right)$

$i$ : Current density $\left(\mathrm{Acm}^{-2}\right)$

$i_{o}^{e f f}$ : Exchange current density at a composite electrode $\left(\mathrm{Acm}^{-2}\right)$

$a_{k}: \mathrm{k}^{\text {th }}$ order polynomial fitting coefficient

$l_{e}:$ Electrolyte thickness $(\mathrm{cm})$

$l_{c(1)}:$ Cathode current collector layer thickness $(\mathrm{cm})$

$l_{c(2)}:$ Cathode functional layer thickness $(\mathrm{cm})$ 
$l_{a(1)}:$ Anode support thickness $(\mathrm{cm})$

$l_{a(2)}$ : Anode functional layer thickness $(\mathrm{cm})$

$\ell_{T P B}:$ Three phase boundary length $\left(\mathrm{cm}^{-1}\right)$

$M_{A}$ : Molecular weight of A

$M_{B}:$ Molecular weight of B

$p:$ Pressure (atm)

$p_{\mathrm{H}_{2}}^{o}$ : Partial pressure of hydrogen in the fuel (atm)

$p_{\mathrm{O}_{2}}^{o}$ : Partial pressure of oxygen in the oxidant (atm)

$p_{\mathrm{H}_{2} \mathrm{O}}^{o}:$ Partial pressure of water vapor in the fuel (atm)

$p_{H_{2}}^{\prime}(i)$ : Partial pressure of hydrogen in the anode close to the anode functional layer/electrolyte interface (atm)

$p_{\mathrm{O}_{2}}^{\prime}(i)$ : Partial pressure of oxygen in the cathode close to the cathode functional layer/electrolyte interface (atm)

$p_{\mathrm{H}_{2} \mathrm{O}}^{\prime}(i)$ : Partial pressure of water vapor in the anode close to the anode functional layer/electrolyte interface (atm)

$R:$ Ideal gas constant $\left(\mathrm{Jmol}^{-1} \mathrm{~K}^{-1}\right)$

$R_{i}:$ Ohmic area specific resistance $\left(\Omega \mathrm{cm}^{2}\right)$

$R_{\text {contact }}$ : Contact resistance associated with the various interfaces between layers $\left(\Omega \mathrm{cm}^{2}\right)$

$R_{c t}^{e f f}:$ Effective charge transfer resistance $\left(\Omega \mathrm{cm}^{2}\right)$

$T:$ Temperature (K)

$V(i)$ : Cell voltage at current density $i(\mathrm{~V})$ 
$V_{v}:$ Volume fraction of porosity

$\alpha$ : Transfer coefficient

$\gamma:$ Temperature coefficient of resistivity $\left(\Omega \mathrm{cmK}^{-1}\right)$

$\sigma:$ Conductivity $\left(\mathrm{Scm}^{-1}\right)$

$\sigma_{A-B}:$ Collision diameter

$\rho_{o}:$ Resistivity at reference temperature of zero $\mathrm{K}(\Omega \mathrm{cm})$

$\rho_{i}$ : Ionic resistivity of the constituent in the composite electrode $(\Omega \mathrm{cm})$

$\rho_{e}^{i o n i c}:$ Ionic resistivity of the electrolyte $(\Omega \mathrm{cm})$

$\rho_{a(1)}^{\text {elect }}:$ Electronic resistivity of the anode support $(\Omega \mathrm{cm})$

$\rho_{a(2)}^{\text {elect }}:$ Electronic resistivity of the anode functional layer $(\Omega \mathrm{cm})$

$\rho_{c(1)}^{\text {elect }}$ : Electronic resistivity of the cathode current collector $(\Omega \mathrm{cm})$

$\rho_{c(2)}^{\text {elect }}:$ Electronic resistivity of the cathode functional layer $(\Omega \mathrm{cm})$

$\rho_{c t}:$ Charge transfer resistivity $(\Omega \mathrm{cm})$

$\eta_{a c t}^{a}:$ Activation polarization at the anode $(\mathrm{V})$

$\eta_{a c t}^{c}:$ Activation polarization at the cathode (V)

$\eta_{\text {conc }}^{a}:$ Concentration polarization at the anode $(\mathrm{V})$

$\eta_{\text {conc }}^{c}$ : Concentration polarization at the cathode $(\mathrm{V})$

$\Omega$ : Collision integral 


\section{References}

1. A. V. Virkar and Y. Jiang, in Solid Oxide Fuel Cells IX, S. C. Singhal and J. Mizusaki, Editors, Electrochemical Society, p. 1057-1067 (2005)

2. S. de Souza, S. J. Visco, and L. C. De Jonghe, J. Electrochem. Soc., 144 (3) 35-37 (1997).

3. J. W. Kim, A. V. Virkar, K-Z. Fung, K. Mehta, and S. C. Singhal, J. Electrochem. Soc., 146 (1) 69-78 (1999).

4. A. V. Virkar, M. C. Williams, S. C. Singhal, and F. Zhao, ECS Transactions, Volume 5, Issue 1, 401-421 (2007).

5. J. D. Kim, G. D. Kim, J. W. Moon, Y. II Park, W. H. Lee, K. Kobayashi, M. Nagai, and C. E. Kim, Solid State Ionics, 143 (3-4) 379-389 (2001).

6. H. Zhu and R. J. Kee, J. Electrochem. Soc., 153 (9) A1765-A1772 (2006).

7. K. Takano, S. Nagata, K. Nozaki, A. Monma, T. Kato, Y. Kaga, A. Negishi, T. Inagaki, H. Yoshida, K. Hosoi, K. Hoshino, T. Akbay and J. Akikusa, J. Power Sources, 132 (1-2) 42-51 (2004).

8. W. G. Bessler, Solid State Ionics, 176 (11-12) 997-1011 (2005).

9. H. Zhu, R. J. Kee, V. M. Janardhanan, O. Deutschmann and D. G. Goodwin, J. Electrochem. Soc., 152 (12) A2427-A2440 (2005).

10. V. M. Janardhanan and O. Deutschmann, Electrochemica Acta, 56 9775-9782 (2011).

11. S. Kakac, A. Pramuanjaroenkij and X. Y. Zhou, Int. J. Hydrogen Energy, 32 761-786 (2007).

12. R. Snieder and J. Trampert, 'Inverse Problems in Geophysics', Wavefield Inversion, International Centre for Mechanical Sciences, Volume 398, 119-190 (1998).

13. F. Zhao and A. V. Virkar, J. Power Sources, 141 (1) 79-95 (2005).

14. Z. Gao, D. Kennouche and S. A. Barnett, J. Power Sources, 260 259-263 (2014).

15. J. A. Labrincha, J. R. Frade and F. M. B. Marques, J. Mat. Sci., 28 3809-3815 (1993).

16. U. Anselmi-Tamburini, G. Chiodelli, M. Arimondi, F. Maglia, G. Spinolo and Z. A. Munir, Solid State Ionics, 110 35-43 (1998). 
17. M. Marinsek, S. Pejovnik and J. Macek, J. European Ceramic Soc., 27 (2-3), 959-964 (2007).

18. J. R. Ferguson, J. M. Fiard and R. Herbin, J. Power Sources, 58 (2) 109-122 (1996).

19. N. F. Bessette, II, W. J. Wepfer and J. Winnick, J. Electrochem. Soc., 142 (11) 37923800 (1995).

20. S. De Souza, S. J. Visco, and L. C. De Jonghe, in Proc. Of $2^{\text {nd }}$ European Solid Oxide Fuel Cell Forum, May 6-10, 1996. Oberrohrdorf, Switzerland.

21. C. Xia and M. Liu, Solid State Ionics, 152-153 423-430 (2002).

22. T. Tsai and S. A. Barnett, Solid State Ionics, 93 (3-4) 207-217 (1997).

23. C. C. T. Yang, W. C. J. Wei and A. Rosen, Materials Chemistry and Physics, 81 (1) 134-142 (2003).

24. T. Dey, D. Singdeo, M. Bose, R. N. Basu and P. C. Ghosh, J. Power Sources, 233 290-298 (2013).

25. Y. Jiang and A. V. Virkar, J. Electrochem. Soc., 150 (7) A942-A951 (2003).

26. F. Zhao, T. J. Armstrong and A. V. Virkar, J. Electrochem. Soc., 150 (3) 249-256 (2003).

27. W. He, K. J. Yoon, R. S. Eriksen, S. Gopalan, S. N. Bose and U. B. Pal, J. Power Sources, 195 532-535 (2010).

28. E. L. Cussler, 'Diffusion: Mass Transfer in Fluid Systems', Cambridge University Press (1995).

29. A. V. Virkar, J. Power Sources, 147 (1-2) 8-31 (2005).

30. R. Radhakrishnan, A. V. Virkar and S. C. Singhal, J. Electrochem. Soc., 152 (5) A927-A936 (2005).

31. R. Radhakrishnan, A. V. Virkar and S. C. Singhal, J. Electrochem. Soc., 152 (1) A210-A218 (2005).

32. C. W. Tanner, K-Z. Fung and A. V. Virkar, J. Electrochem. Soc., 144 (1) 21-30 (1997).

33. F. Zhao, Y. Jiang, G. Y. Lin and A. V. Virkar,SOFC-VII, Electrochemical Society, edited by S. C. Singhal and H. Yokokawa, 501-510 (2001). 
34. A. Bieberle, L. P. Meier and L. J. Gauckler, J. Electrochem. Soc., 148 (6) 646-656 (2001).

35. M. Vogler, A. Bieberle-Hutter, L. Gauckler, J. Warnutz and W. G. Bessler, J. Electrochem. Soc., 156 (5) B663-B672 (2009). 
Table 1: Polynomial Fits for Cell Data in Figure 1 at $800^{\circ} \mathrm{C}$.

\begin{tabular}{|l|l|l|l|l|l|l|l|l|l|l|l|}
\hline Order & $\mathrm{a}_{0}$ & $\mathrm{a}_{1}$ & $\mathrm{a}_{2}$ & $\mathrm{a}_{3}$ & $\mathrm{a}_{4}$ & $\mathrm{a}_{5}$ & $\mathrm{a}_{6}$ & $\mathrm{a}_{7}$ & $\mathrm{a}_{8}$ & $\mathrm{a}_{9}$ & rmse \\
\hline 2 & 1.0737 & -0.344 & 0.0409 & & & & & & & & 0.0057 \\
\hline 3 & 1.0789 & -0.372 & 0.0665 & -0.059 & & & & & & & 0.0045 \\
\hline 4 & 1.0821 & -0.403 & 0.117 & -0.033 & 0.0046 & & & & & & 0.004 \\
\hline 5 & 1.0861 & -0.459 & 0.2629 & -0.168 & 0.056 & -0.007 & & & & & 0.0032 \\
\hline 6 & 1.09 & -0.537 & 0.5573 & -0.591 & 0.334 & -0.091 & 0.0095 & & & & 0.0021 \\
\hline 7 & 1.0917 & -0.585 & 0.81 & -1.126 & 0.858 & -0.354 & 0.0751 & -0.006 & & & 0.0017 \\
\hline 8 & 1.0925 & -0.615 & 1.0298 & -1.711 & 1.6504 & -0.938 & 0.3127 & -0.057 & 0.0043 & & 0.0017 \\
\hline 9 & 1.0934 & -0.667 & 1.5322 & -3.553 & 5.0127 & -4.368 & 2.3614 & -0.767 & 0.1368 & -0.01 & 0.0015 \\
\hline
\end{tabular}

Table 2. Electrical conductivities of cell components

$$
\sigma\left(S . \mathrm{cm}^{-1}\right) \quad \text { References }
$$

Anode support $\left(\mathrm{Ni}+\mathrm{YSZ}, 38 \mathrm{vol} . \% \mathrm{Ni} \quad\left(1.03 \times 10^{-2}+3 \times 10^{-5} T\right)^{-1}\right.$

)

Anode functional layer

$\left(2.70 \times 10^{-2}+5 \times 10^{-6} T\right)^{-1}$

$(\mathrm{Ni}+\mathrm{YSZ}, 26$ vol.\% Ni )

Electrolyte (YSZ )

$$
\frac{3.60 \times 10^{5}}{T} \exp \left(\frac{-85.63 \times 10^{3}}{R T}\right)
$$

Electrolyte (GDC)

$$
\frac{4.62 \times 10^{4}}{T} \exp \left(\frac{-58.48 \times 10^{3}}{R T}\right)
$$

Cathode functional layer

$$
\frac{2.94 \times 10^{4}}{T} \exp \left(\frac{-17.40 \times 10^{3}}{R T}\right)
$$

$50 \% L S M+Y S Z$

Cathode current collector (LSM)

$$
\frac{1.02 \times 10^{4}}{T} \exp \left(\frac{-9.58 \times 10^{3}}{R T}\right)
$$


Table 3 Measured and calculated ohmic resistance for different cells at $800^{\circ} \mathrm{C}$

Anode support thickness $1 \mathrm{~mm}$, anode interlayer thickness $20 \mu \mathrm{m}$, cathode functional layer thickness $20 \mu \mathrm{m}$, cathode current collector thickness $50 \mu \mathrm{m}$

Electrolyte thickness ( $\mu \mathrm{m})$

$4 \quad 8$

15

20

Measured ohmic resistance [13] $\left(\Omega \mathrm{cm}^{2}\right)$

0.10

0.104

0.114

0.14

Estimated ohmic resistance (5 layers)

0.043

0.053

0.069

0.081

$\left(\Omega \mathrm{cm}^{2}\right)$

Estimated contact resistance $\left(\Omega \mathrm{cm}^{2}\right)$

$0.057 \quad 0.051$

0.045

0.059

Estimated contact resistance \% of

57

49

39

42

Total ohmic resistance

Anode interlayer thickness $20 \mu \mathrm{m}$, electrolyte thickness $8 \mu \mathrm{m}$, cathode functional layer thickness $20 \mu \mathrm{m}$, cathode current collector thickness $50 \mu \mathrm{m}$

$\begin{array}{lcccc}\text { Anode support thickness (mm) } & 0.5 & 1.0 & 1.5 & 2.45 \\ \text { Measured ohmic resistance [13] }\left(\Omega \mathrm{cm}^{2}\right) & 0.095 & 0.104 & 0.13 & 0.14 \\ \text { Estimated ohmic resistance (5 layers) } & 0.041 & 0.053 & 0.064 & 0.087 \\ \left(\Omega \mathrm{cm}^{2}\right) & & & & \\ \text { Estimated contact resistance }\left(\Omega \mathrm{cm}^{2}\right) & 0.054 & 0.051 & 0.066 & 0.053 \\ \text { Estimated contact resistance \% of } & 57 & 49 & 51 & 38 \\ \text { Total ohmic resistance } & & & & \end{array}$

Note: The average percentage of the calculated contact resistance from the eight cells is $\sim 48 \%$ with a standard deviation of $\sim 7 \%$. 


\section{Figure Captions:}

Figure 1: (a) Experimental cell performance data from [13]. (b) Polynomial fits to the cell test data at $800^{\circ} \mathrm{C}$ from degree 2 to degree 9.

Figure 2: Measured electrical resistivity of $\mathrm{Ni}+\mathrm{YSZ}$ anodes containing various volume fractions of $\mathrm{Ni}$ as a function of temperature $[16,17]$.

Figure 3: A schematic showing measurement of effective diffusivities through porous bodies and the calculation of concentration polarizations.

Figure 4: A schematic of a five layer cell and the variation of partial pressures of $\mathrm{H}_{2}$ and $\mathrm{H}_{2} \mathrm{O}$ through the anode and the variation of partial pressure of $\mathrm{O}_{2}$ through the cathode.

Figure 5: Plot of charge transfer resistivity, $\rho_{c t}$, for Ni/YSZ vs. $1 / \sqrt{p_{H_{2}}}$ using data from Bieberle et al. [34].

Figure 6: A schematic showing measurement of charge transfer resistivities on patterned electrodes and the calculation of activation polarizations.

Figure 7: Flow diagram of the procedure used for calculations.

Figure 8: (a) A plot of hydrogen partial pressure, $p_{H_{2}}^{\prime}(i)$, at the anode functional layer/electrolyte interface in a cell with $2 \mu \mathrm{m}$ electrode grain size as a function of current density, $i$. As the current density increases, the partial pressure at the interface decreases, 
its lowest value approaching zero (but not exactly zero to ensure gas phase equilibrium). (b) A plot of oxygen partial pressure, $p_{O_{2}}^{\prime}(i)$, at the cathode functional layer/electrolyte interface in a cell with $2 \mu \mathrm{m}$ electrode grain size microstructure as a function of current density, $i$. As the current density increases, the partial pressure at the interface decreases, its lowest value approaching zero (but not exactly zero consistent with Nernst potential). Cell details: Ni + YSZ anode support: $1 \mathrm{~mm}$ thick. LSM cathode current collector layer: $50 \mu \mathrm{m}$ thick.

Figure 9: (a) Calculated effective exchange current density at the anode, $i_{o(a)}^{e f f}$, as a function of current density for a cell with $2 \mu \mathrm{m}$ electrode grain size. As the current density increases, the $p_{H_{2}}^{\prime}(i)$ decreases, which increases the charge transfer resistivity and thus the exchange current decreases. (b) Calculated effective exchange current density at the cathode, $i_{o(c)}^{e f f}$, as a function of current density for a cell with $2 \mu \mathrm{m}$ electrode grain size. As the current density increases, the $p_{O_{2}}^{\prime}(i)$ decreases, which increases the charge transfer resistivity and thus the exchange current density decreases. Cell details: $\mathrm{Ni}+$ YSZ anode support: $1 \mathrm{~mm}$ thick. LSM cathode current collector layer: $50 \mu \mathrm{m}$ thick.

Figure 10: (a) Calculated activation polarization at the anode, $\eta_{a c t}^{a}$, as a function of current density for a cell with $2 \mu \mathrm{m}$ electrode grain size. (b) Calculated activation polarization at the cathode, $\eta_{a c t}^{c}$, as a function of current density for a cell with $2 \mu \mathrm{m}$ 
electrode grain size. Cell details: $\mathrm{Ni}+$ YSZ anode support: $1 \mathrm{~mm}$ thick. LSM cathode current collector layer: $50 \mu \mathrm{m}$ thick.

Figure 11: (a) Calculated polarizations at $800^{\circ} \mathrm{C}$ for a 5 layer cell with $8 \mu \mathrm{m}$ thick YSZ electrolyte, anode support thickness $1 \mathrm{~mm}$, cathode current collector thickness $50 \mu \mathrm{m}$, cathode and anode functional layer grain size of $2 \mu \mathrm{m}$ and functional layer thicknesses of $15 \mathrm{~d}=30 \mu \mathrm{m}$. The ohmic resistance is $0.1 \Omega \mathrm{cm}^{2}$. At lower current densities the activation polarizations dominate. At higher current densities the ohmic polarization dominates. (b) The corresponding voltage vs. current density and power density vs. current density plots.

Figure 12: (a) Calculated polarizations at $800^{\circ} \mathrm{C}$ for a 5 layer cell with $8 \mu \mathrm{m}$ thick YSZ electrolyte, anode support thickness $1 \mathrm{~mm}$, cathode current collector thickness $50 \mu \mathrm{m}$, cathode and anode functional layer grain size of $0.2 \mu \mathrm{m}$ and functional layer thicknesses of $15 \mathrm{~d}=3 \mu \mathrm{m}$. The ohmic resistance is $0.1 \Omega \mathrm{cm}^{2}$. The ohmic polarization dominates over the entire current density range. (b) The corresponding voltage vs. current density and power density vs. current density plots.

Figure 13: (a) Calculated polarizations at $800^{\circ} \mathrm{C}$ for a 5 layer cell with $8 \mu \mathrm{m}$ thick YSZ electrolyte, anode support thickness $1 \mathrm{~mm}$, cathode current collector thickness $50 \mu \mathrm{m}$, cathode and anode functional layer grain size of $0.02 \mu \mathrm{m}$ and functional layer thicknesses of $15 \mathrm{~d}=0.3 \mu \mathrm{m}$. The ohmic resistance is $0.1 \Omega \mathrm{cm}^{2}$. The ohmic polarization dominates over the entire current density range. (b) The corresponding voltage vs. current density and power density vs. current density plots. 
Figure 14: (a) Calculated polarizations at $800^{\circ} \mathrm{C}$ for a 5 layer cell with $8 \mu \mathrm{m}$ thick YSZ electrolyte, anode support thickness $0.5 \mathrm{~mm}$, cathode current collector thickness $50 \mu \mathrm{m}$, cathode and anode functional layer grain size of $0.02 \mu \mathrm{m}$ and functional layer thicknesses of $15 \mathrm{~d}=0.3 \mu \mathrm{m}$. The anode concentration polarization is lower than in Figure 13(a) because of the smaller anode support thickness. The ohmic resistance is $0.1 \Omega \mathrm{cm}^{2}$. The ohmic polarization dominates over the entire current density range. (b) The corresponding voltage vs. current density and power density vs. current density plots.

Figure 15: (a) Calculated polarizations at $800^{\circ} \mathrm{C}$ for a 5 layer cell with $8 \mu \mathrm{m}$ thick YSZ electrolyte, anode support thickness $0.1 \mathrm{~mm}$, cathode current collector thickness $50 \mu \mathrm{m}$, cathode and anode functional layer grain size of $0.02 \mu \mathrm{m}$ and functional layer thicknesses of $15 \mathrm{~d}=0.3 \mu \mathrm{m}$. The anode concentration polarization is lower than in Figure 14(a) because of the smaller anode support thickness. The ohmic resistance is $0.1 \Omega \mathrm{cm}^{2}$. The ohmic polarization dominates over the entire current density range. (b) The corresponding voltage vs. current density and power density vs. current density plots.

Figure 16: A comparison of experimental cell tests measurements from Zhao and Virkar [13] (symbols) with calculated performance curves using measurements made on cell materials and cell components, and using the parametric model.

Figure 17: Calculated performance curves as a function of temperature for a cell with YSZ electrolyte of $8 \mu \mathrm{m}$ in thickness and electrode grain size of $2 \mu \mathrm{m}$. 
Figure 18: Calculated performance curves as a function of temperature for a cell with YSZ electrolyte of $8 \mu \mathrm{m}$ in thickness and electrode grain size of $0.2 \mu \mathrm{m}$.

Figure 19: Calculated performance curves as a function of temperature for a cell with GDC electrolyte of $8 \mu \mathrm{m}$ in thickness and electrode grain size of $2 \mu \mathrm{m}$.

Figure 20: Calculated performance curves as a function of temperature for a cell with GDC electrolyte of $8 \mu \mathrm{m}$ in thickness and electrode grain size of $0.2 \mu \mathrm{m}$. 

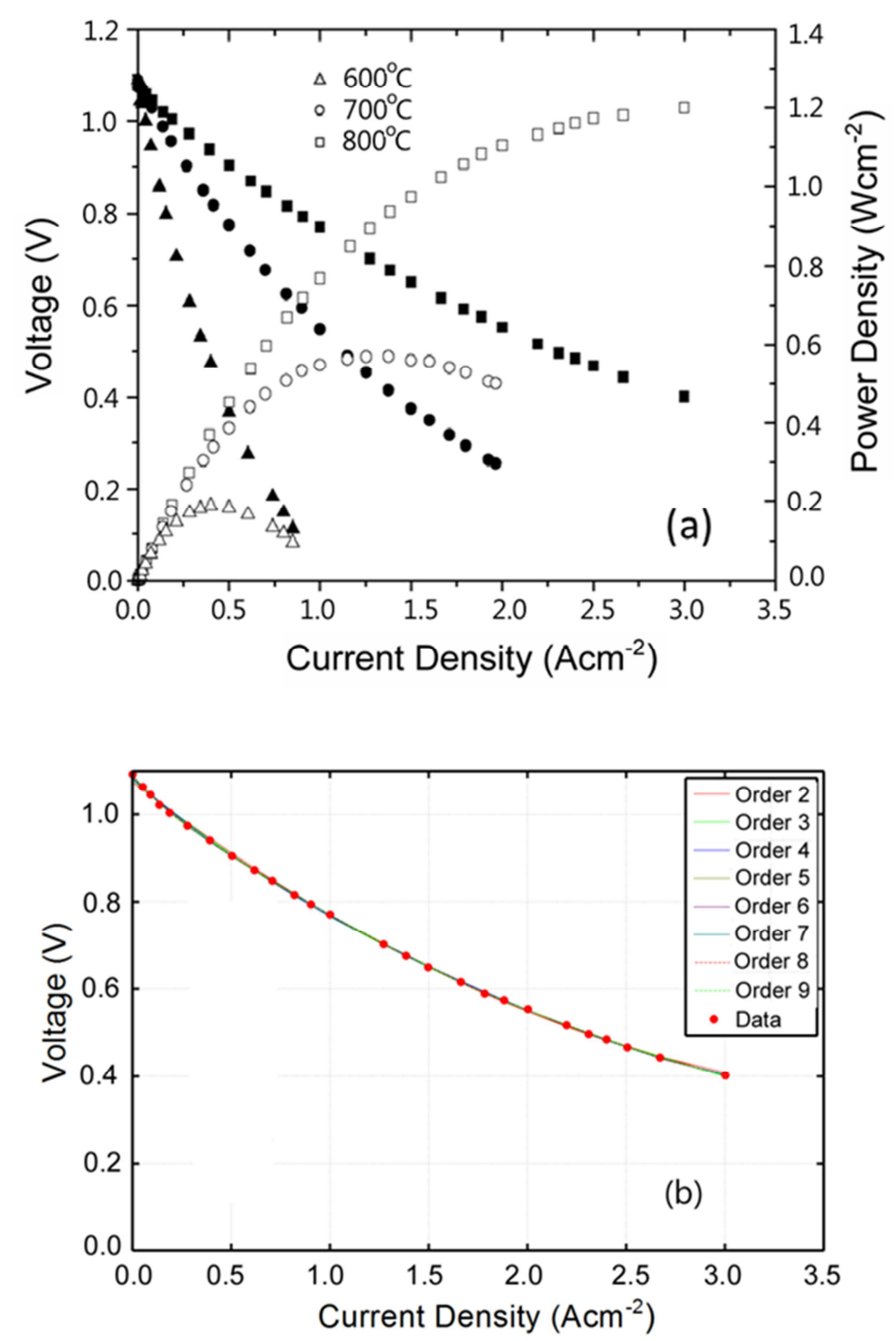

Figure 1: (a) Experimental cell performance data from [13]. (b) Polynomial fits to the cell test data at $800^{\circ} \mathrm{C}$ from degree 2 to degree 9. 


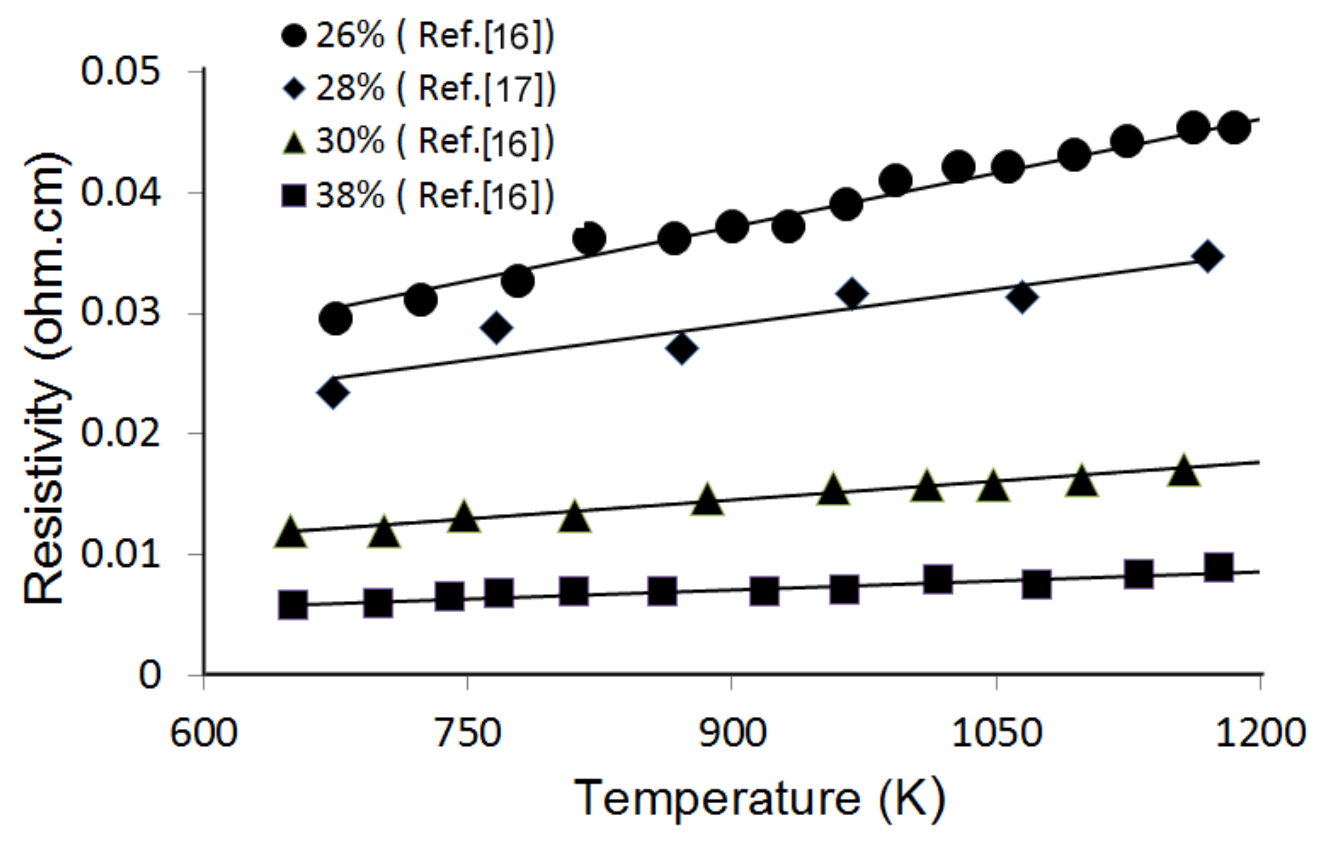

Figure 2: Measured electrical resistivity of $\mathrm{Ni}+\mathrm{YSZ}$ anodes containing various volume fractions of $\mathrm{Ni}$ as a function of temperature $[16,17]$. 


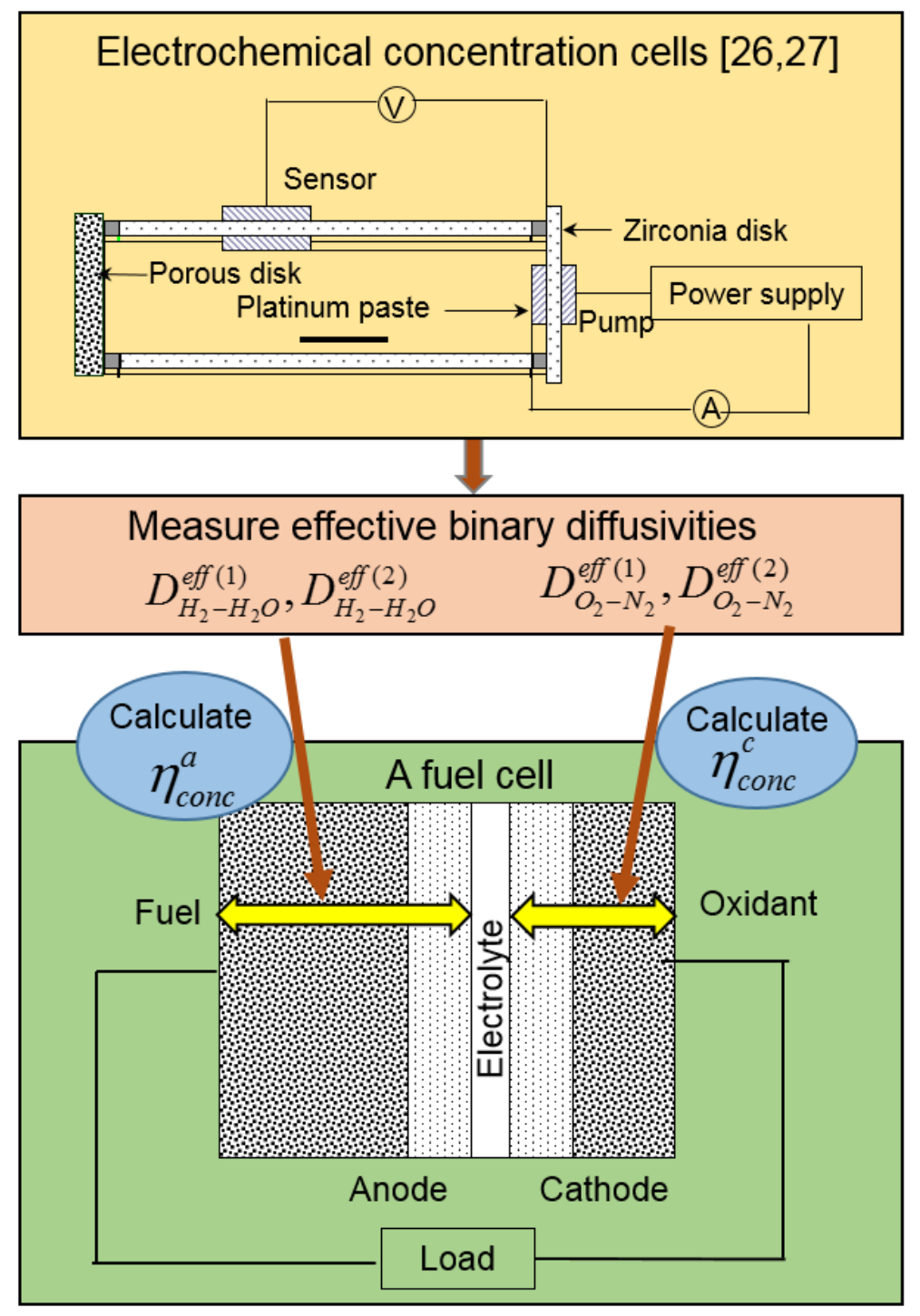

Figure 3: A schematic showing measurement of effective diffusivities through porous bodies and the calculation of concentration polarizations. 


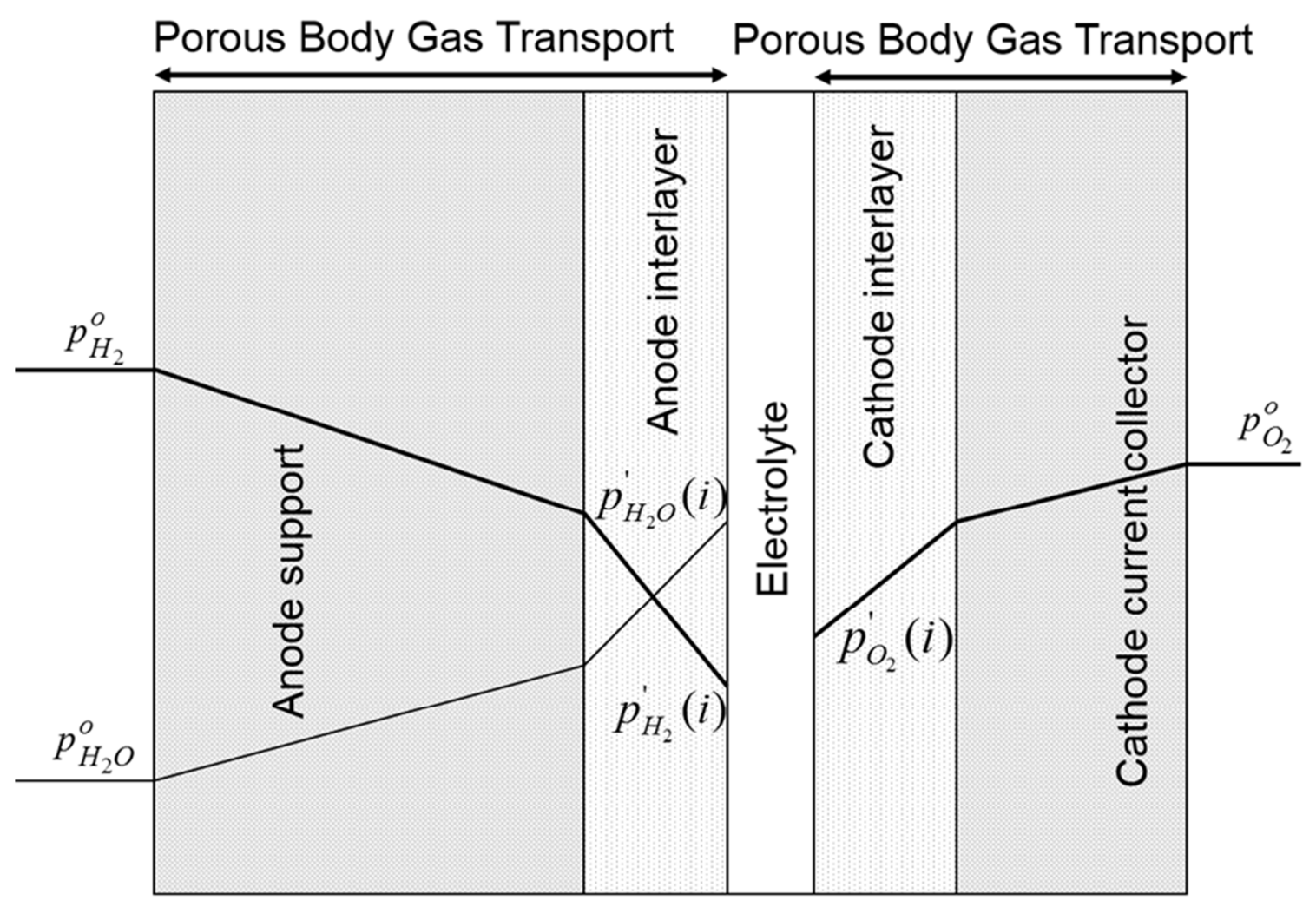

Figure 4: A schematic of a five layer cell and the variation of partial pressures of $\mathrm{H}_{2}$ and $\mathrm{H}_{2} \mathrm{O}$ through the anode and the variation of partial pressure of $\mathrm{O}_{2}$ through the cathode. 


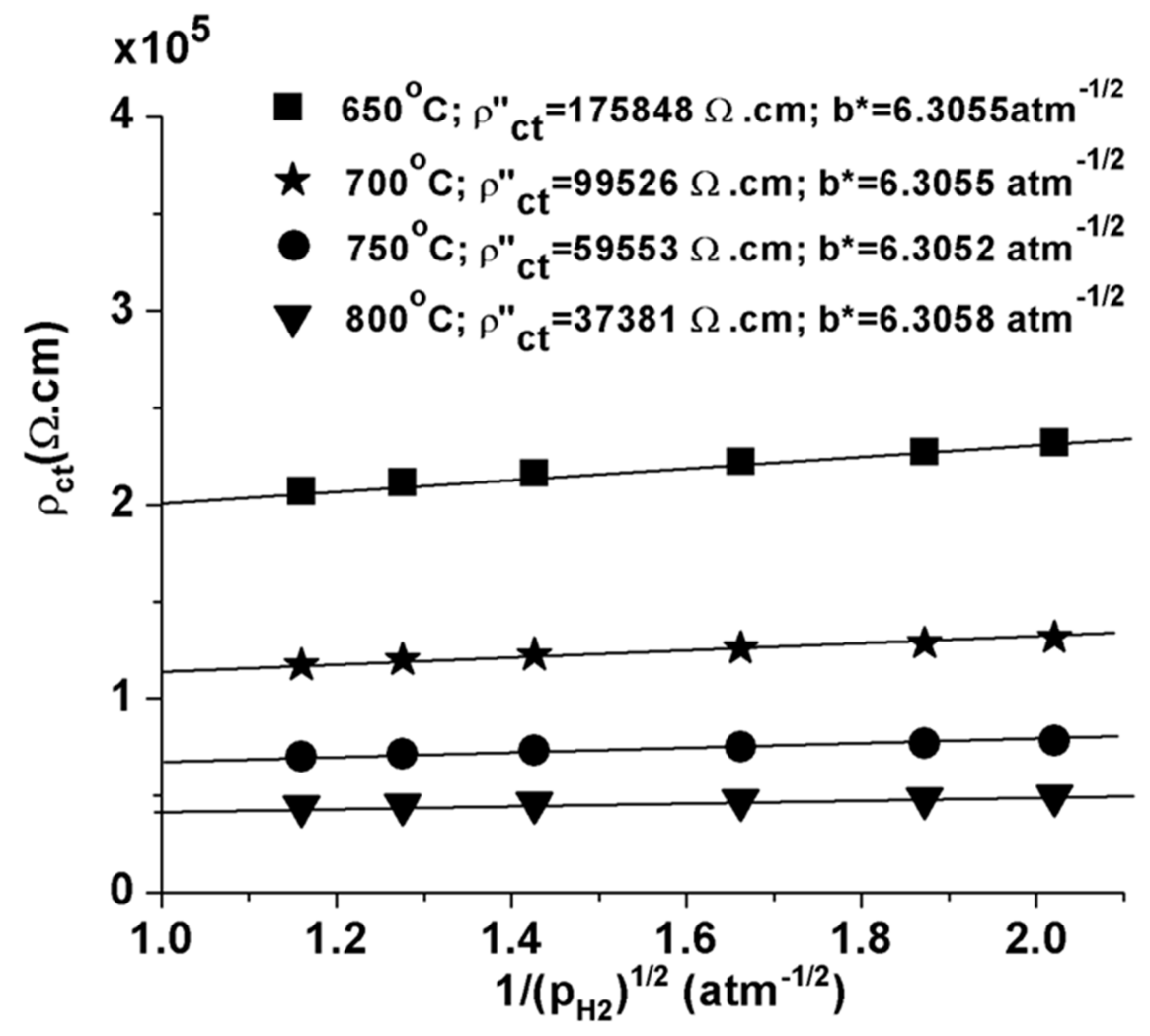

Figure 5: Plots of charge transfer resistivity, $\rho_{c t}$, for Ni/YSZ vs. $1 / \sqrt{p_{H_{2}}}$ using data from Bieberle et al. [34]. 


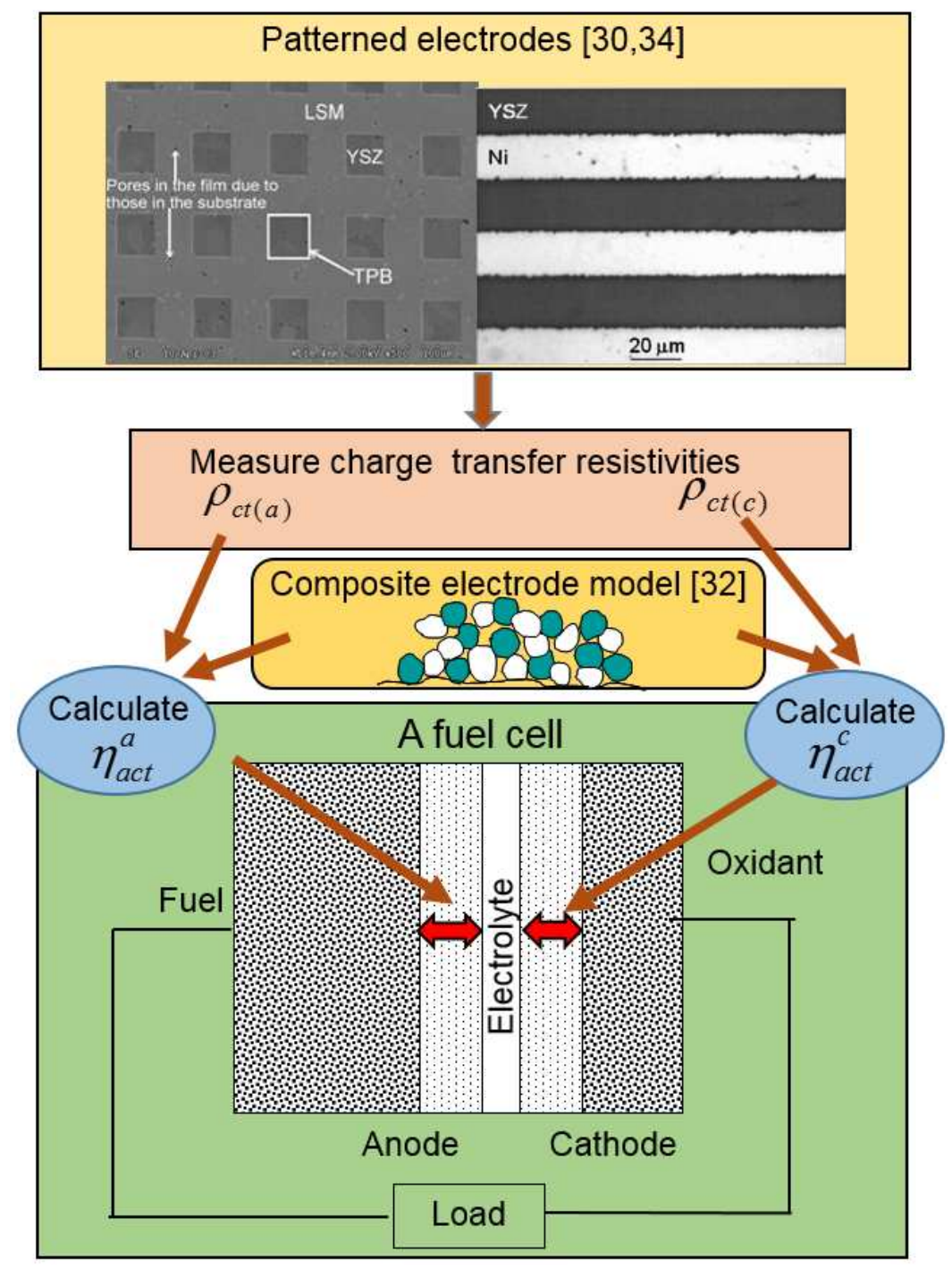

Figure 6: A schematic showing measurement of charge transfer resistivities on patterned electrodes and the calculation of activation polarizations. 


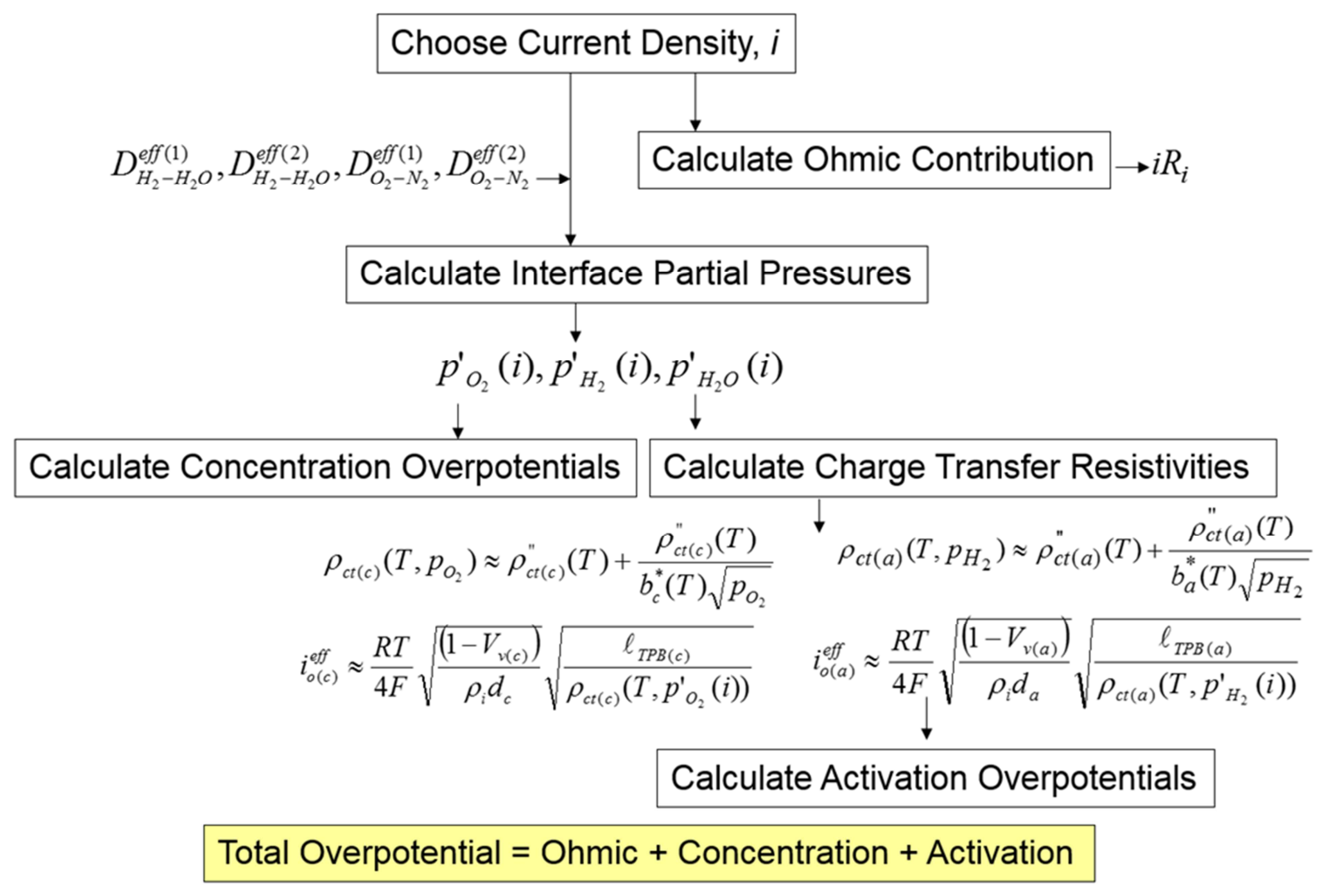

Figure 7: A flow diagram of the procedure used for calculations. 

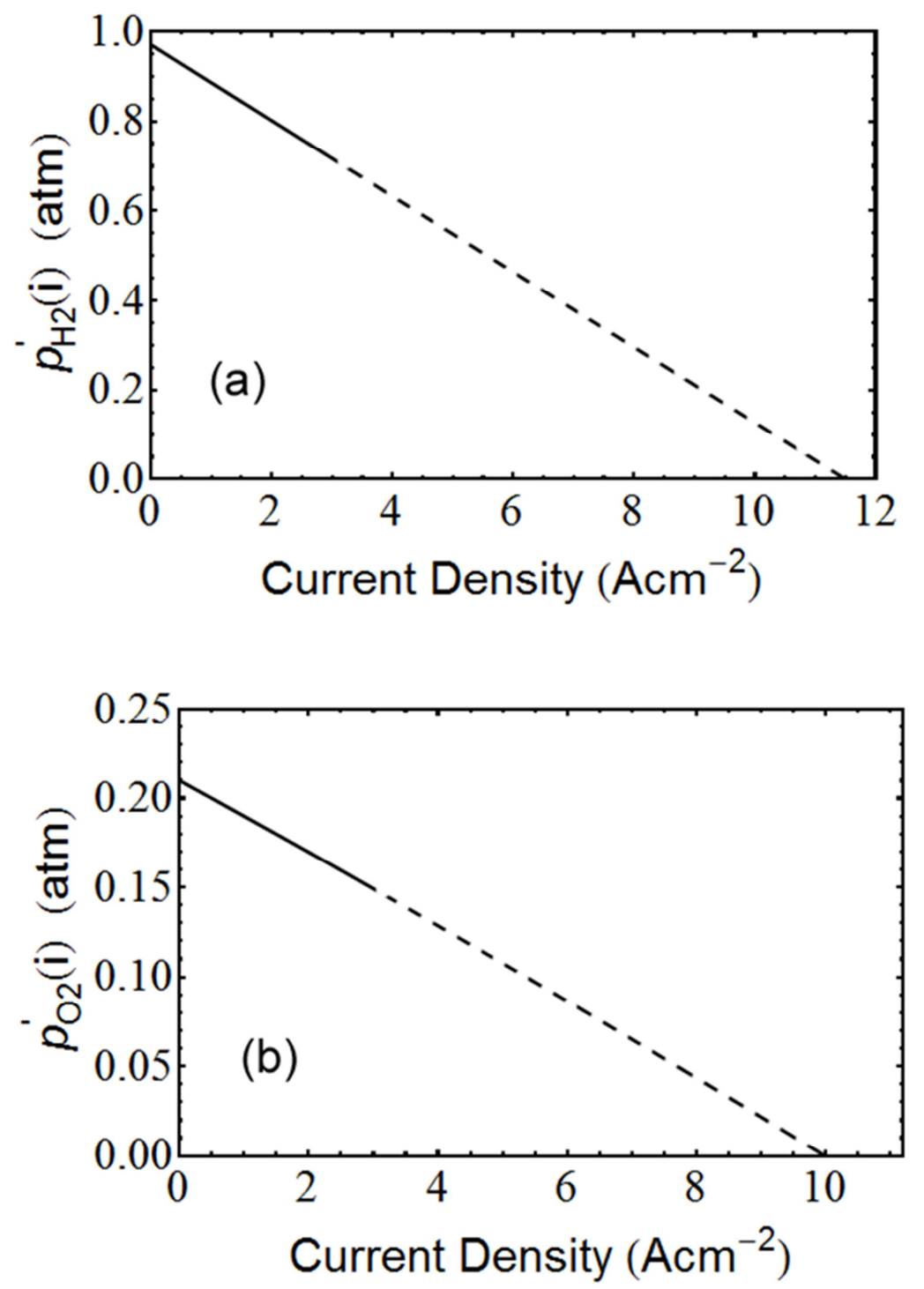

Figure 8: (a) A plot of hydrogen partial pressure, $p_{H_{2}}^{\prime}(i)$, at the anode functional layer/electrolyte interface in a cell with $2 \mu \mathrm{m}$ electrode grain size as a function of current density, $i$. As the current density increases, the partial pressure at the interface decreases, its lowest value approaching zero (but not exactly zero to ensure gas phase equilibrium). (b) A plot of oxygen partial pressure, $p_{\mathrm{O}_{2}}^{\prime}(i)$, at the cathode functional layer/electrolyte interface in a cell with $2 \mu \mathrm{m}$ electrode grain size microstructure as a function of current density, $i$. As the current density increases, the partial pressure at the interface decreases, its lowest value approaching zero (but not exactly zero consistent with Nernst potential). Cell details: $\mathrm{Ni}+$ YSZ anode support: $1 \mathrm{~mm}$ thick. LSM cathode current collector layer: $50 \mu \mathrm{m}$ thick. 

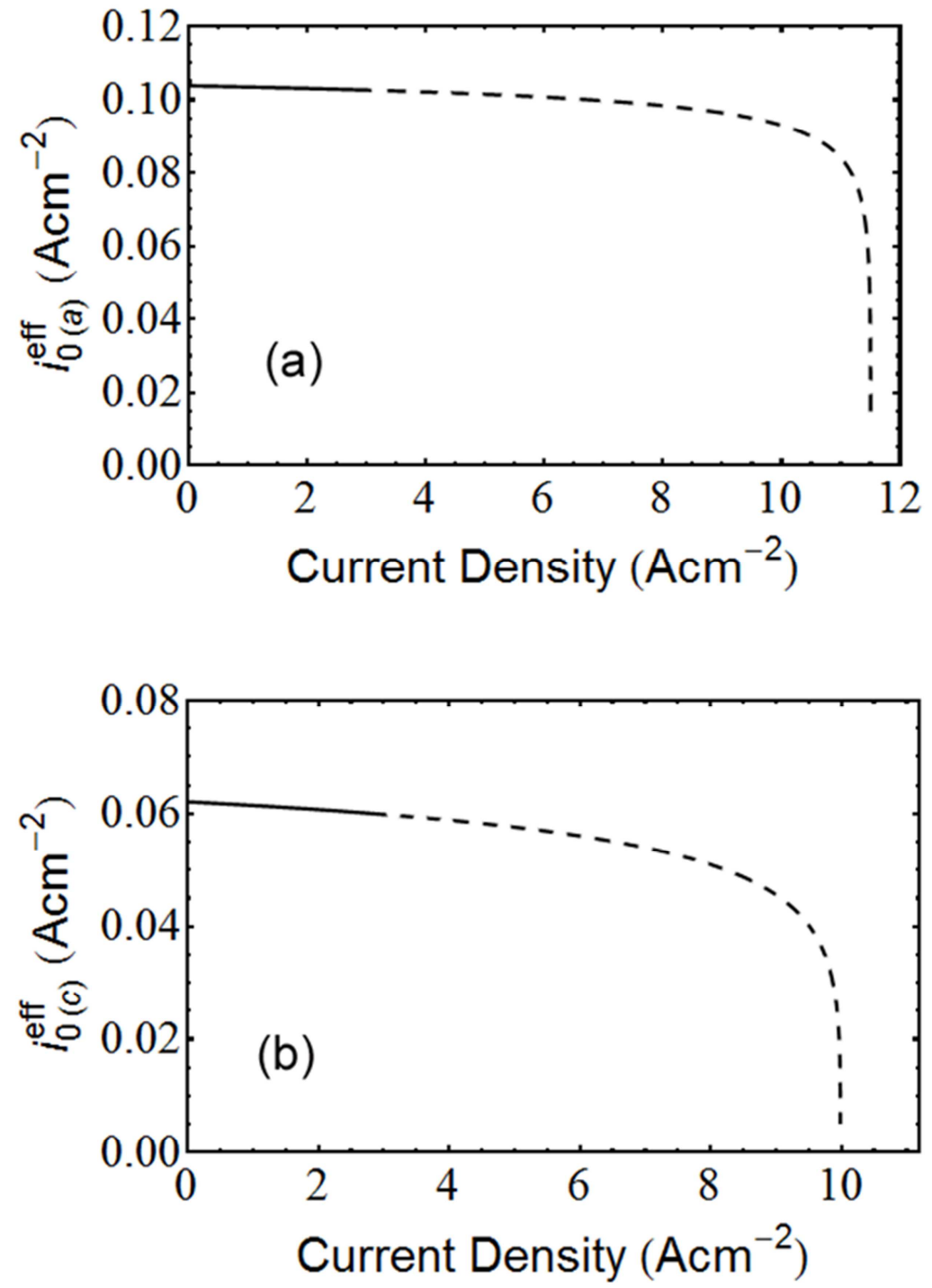

Figure 9: (a) Calculated effective exchange current density at the anode, $i_{o(a)}^{e f f}$, as a function of current density for a cell with $2 \mu \mathrm{m}$ electrode grain size. As the current density increases, the $p_{H_{2}}^{\prime}(i)$ decreases, which increases the charge transfer resistivity and thus the exchange current decreases. (b) Calculated effective exchange current density at the cathode, $i_{o(c)}^{e f f}$, as a function of current density for a cell with $2 \mu \mathrm{m}$ electrode grain size. As the current density increases, the $p_{O_{2}}^{\prime}(i)$ decreases, which increases the charge transfer resistivity and thus the exchange current density decreases. Cell details: Ni + YSZ anode support: $1 \mathrm{~mm}$ thick. LSM cathode current collector layer: $50 \mu \mathrm{m}$ thick. 

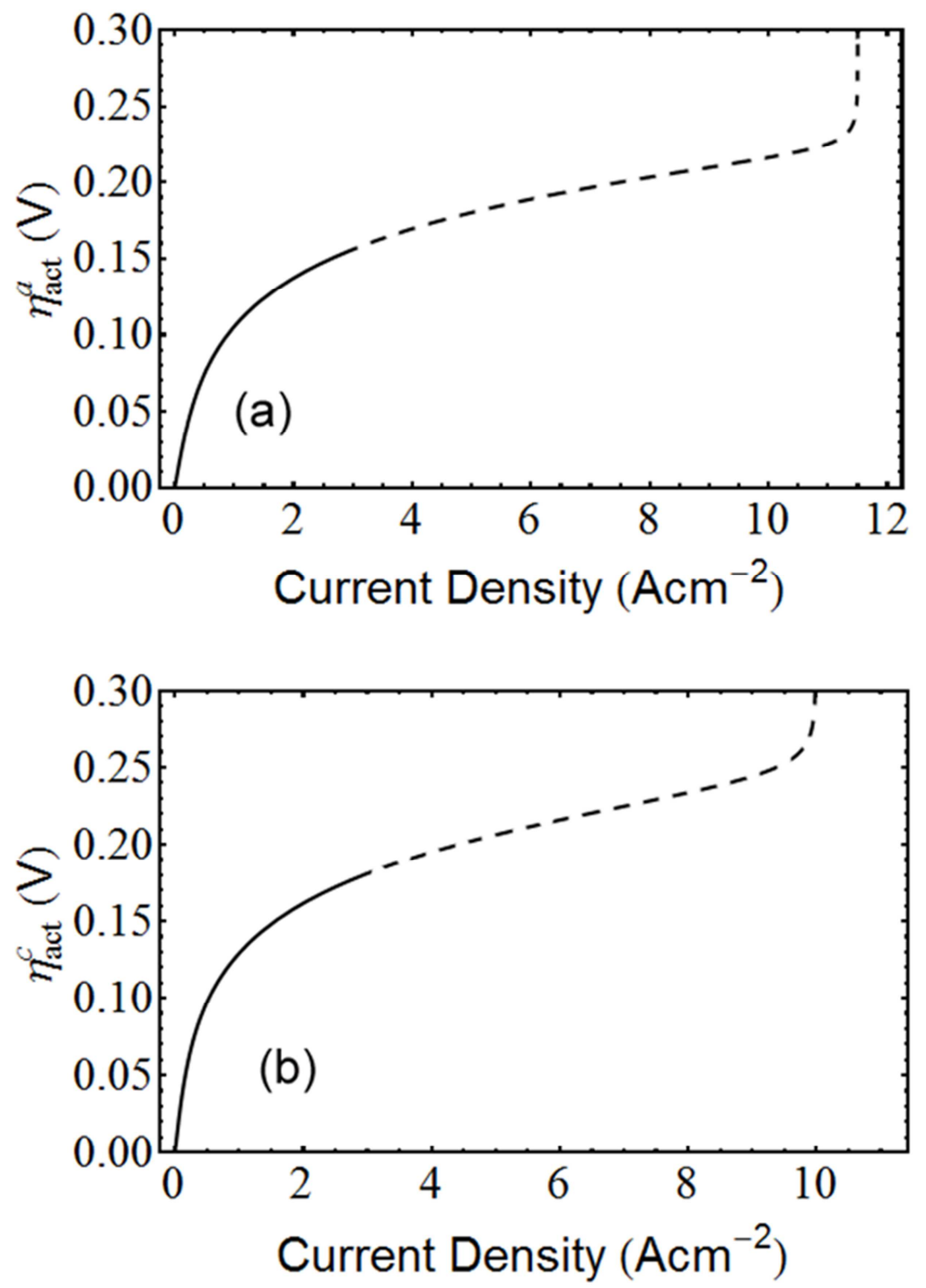

Figure 10: (a) Calculated activation polarization at the anode, $\eta_{a c t}^{a}$, as a function of current density for a cell with $2 \mu \mathrm{m}$ electrode grain size. (b) Calculated activation polarization at the cathode, $\eta_{a c t}^{c}$, as a function of current density for a cell with $2 \mu \mathrm{m}$ electrode grain size. Cell details: Ni + YSZ anode support: $1 \mathrm{~mm}$ thick. LSM cathode current collector layer: $50 \mu \mathrm{m}$ thick. 

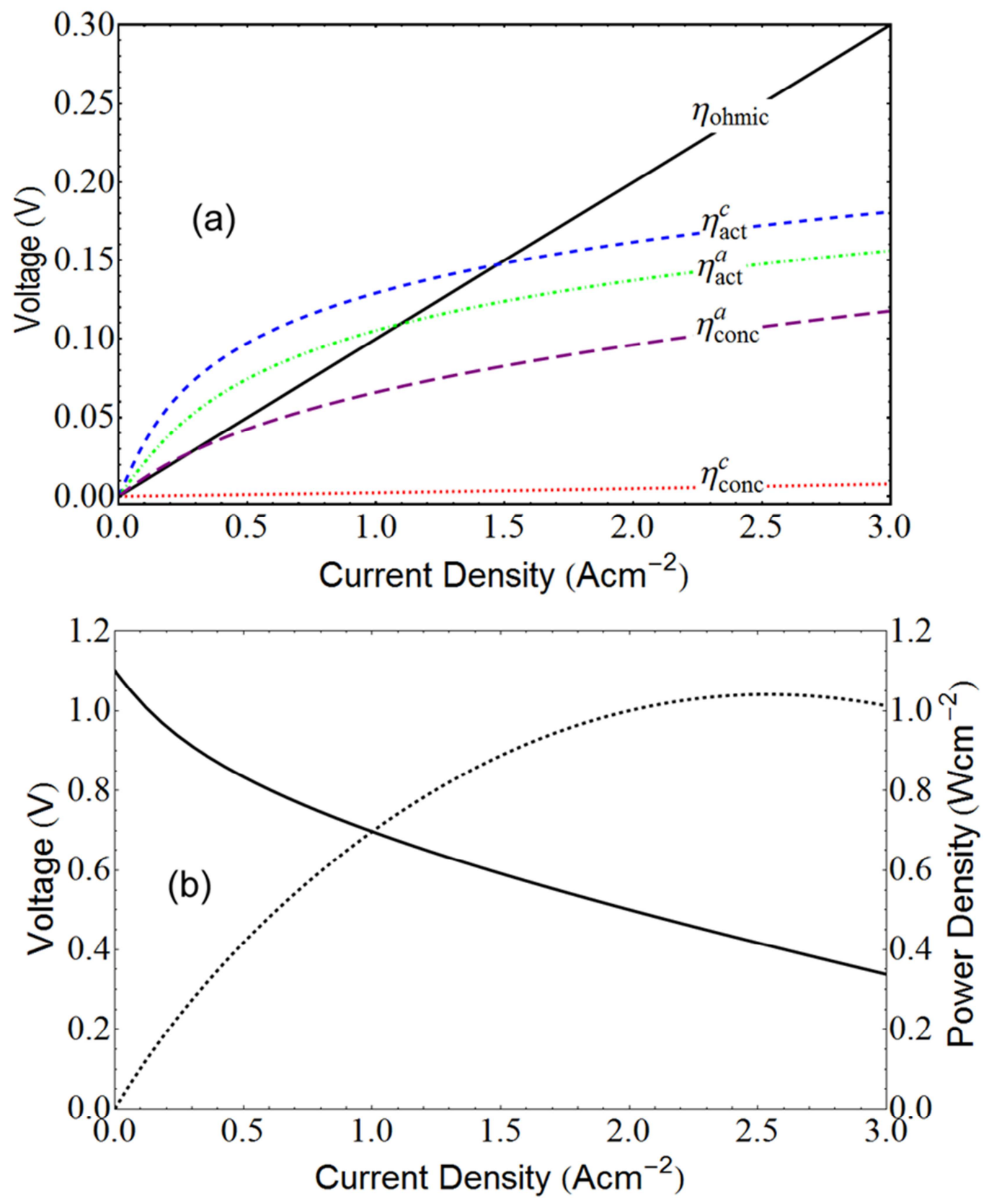

Figure 11: (a) Calculated polarizations at $800^{\circ} \mathrm{C}$ for a 5 layer cell with $8 \mu \mathrm{m}$ thick YSZ electrolyte, anode support thickness $1 \mathrm{~mm}$, cathode current collector thickness $50 \mu \mathrm{m}$, cathode and anode functional layer grain size of $2 \mu \mathrm{m}$ and functional layer thicknesses of $15 \mathrm{~d}=30 \mu \mathrm{m}$. The ohmic resistance is $0.1 \Omega \mathrm{cm}^{2}$. At lower current densities the activation polarizations dominate. At higher current densities the ohmic polarization dominates. (b) The corresponding voltage vs. current density and power density vs. current density plots. 

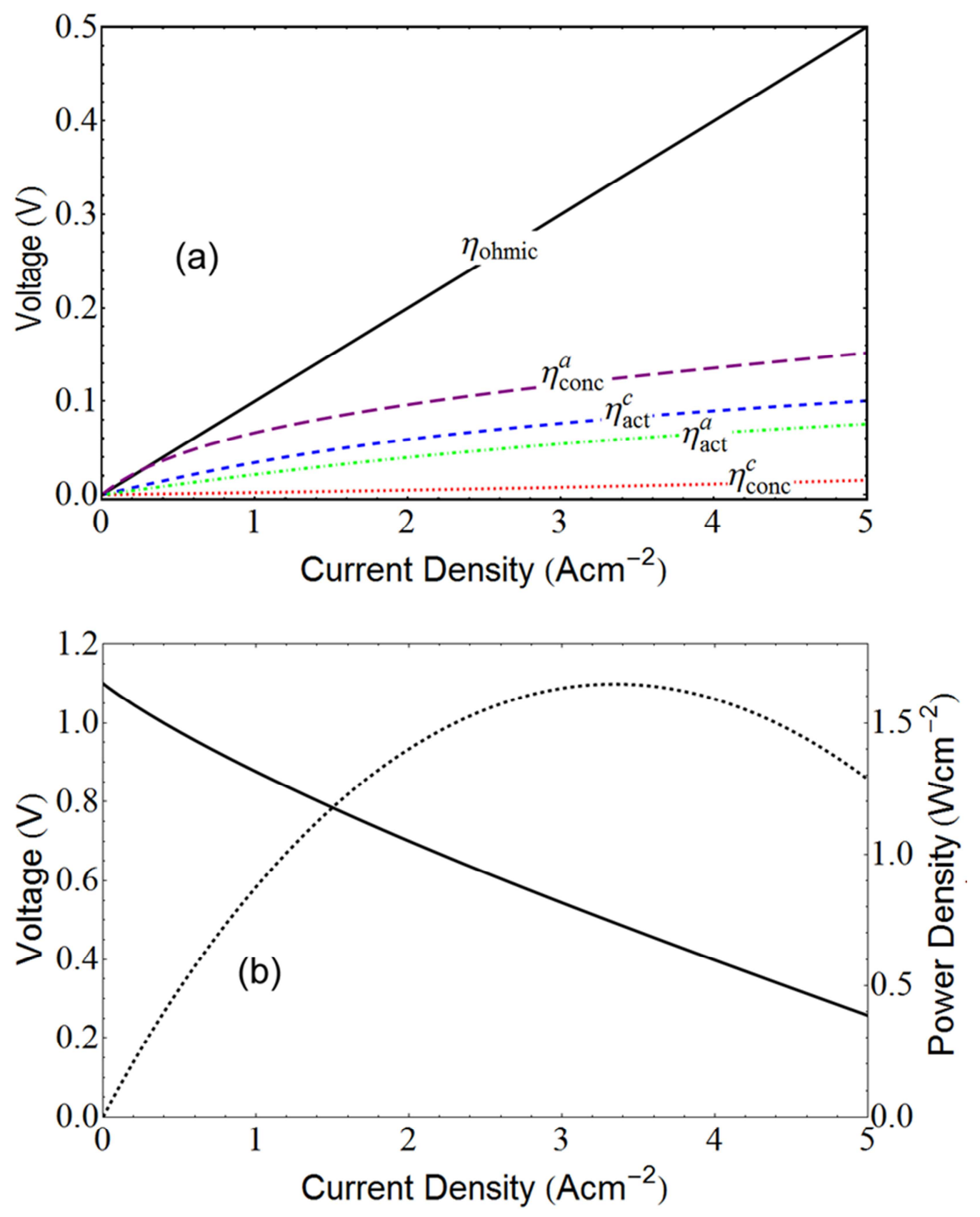

Figure 12: (a) Calculated polarizations at $800^{\circ} \mathrm{C}$ for a 5 layer cell with $8 \mu \mathrm{m}$ thick YSZ electrolyte, anode support thickness $1 \mathrm{~mm}$, cathode current collector thickness $50 \mu \mathrm{m}$, cathode and anode functional layer grain size of $0.2 \mu \mathrm{m}$ and functional layer thicknesses of $15 \mathrm{~d}=3 \mu \mathrm{m}$. The ohmic resistance is $0.1 \Omega \mathrm{cm}^{2}$. The ohmic polarization dominates over the entire current density range. (b) The corresponding voltage vs. current density and power density vs. current density plots. 

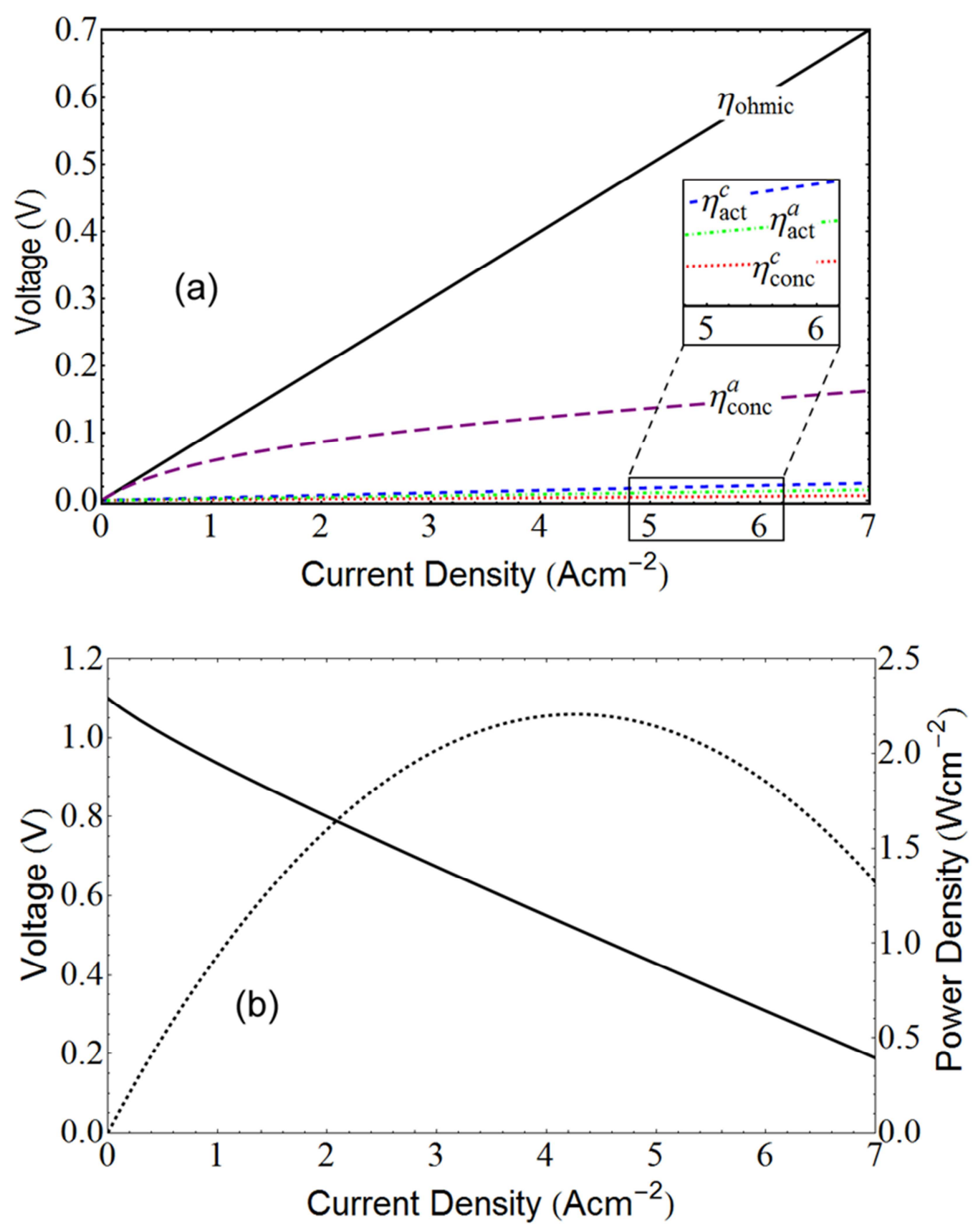

Figure 13: (a) Calculated polarizations at $800^{\circ} \mathrm{C}$ for a 5 layer cell with $8 \mu \mathrm{m}$ thick YSZ electrolyte, anode support thickness $1 \mathrm{~mm}$, cathode current collector thickness $50 \mu \mathrm{m}$, cathode and anode functional layer grain size of $0.02 \mu \mathrm{m}$ and functional layer thicknesses of $15 \mathrm{~d}=0.3 \mu \mathrm{m}$. The ohmic resistance is $0.1 \Omega \mathrm{cm}^{2}$. The ohmic polarization dominates over the entire current density range. (b) The corresponding voltage vs. current density and power density vs. current density plots. 

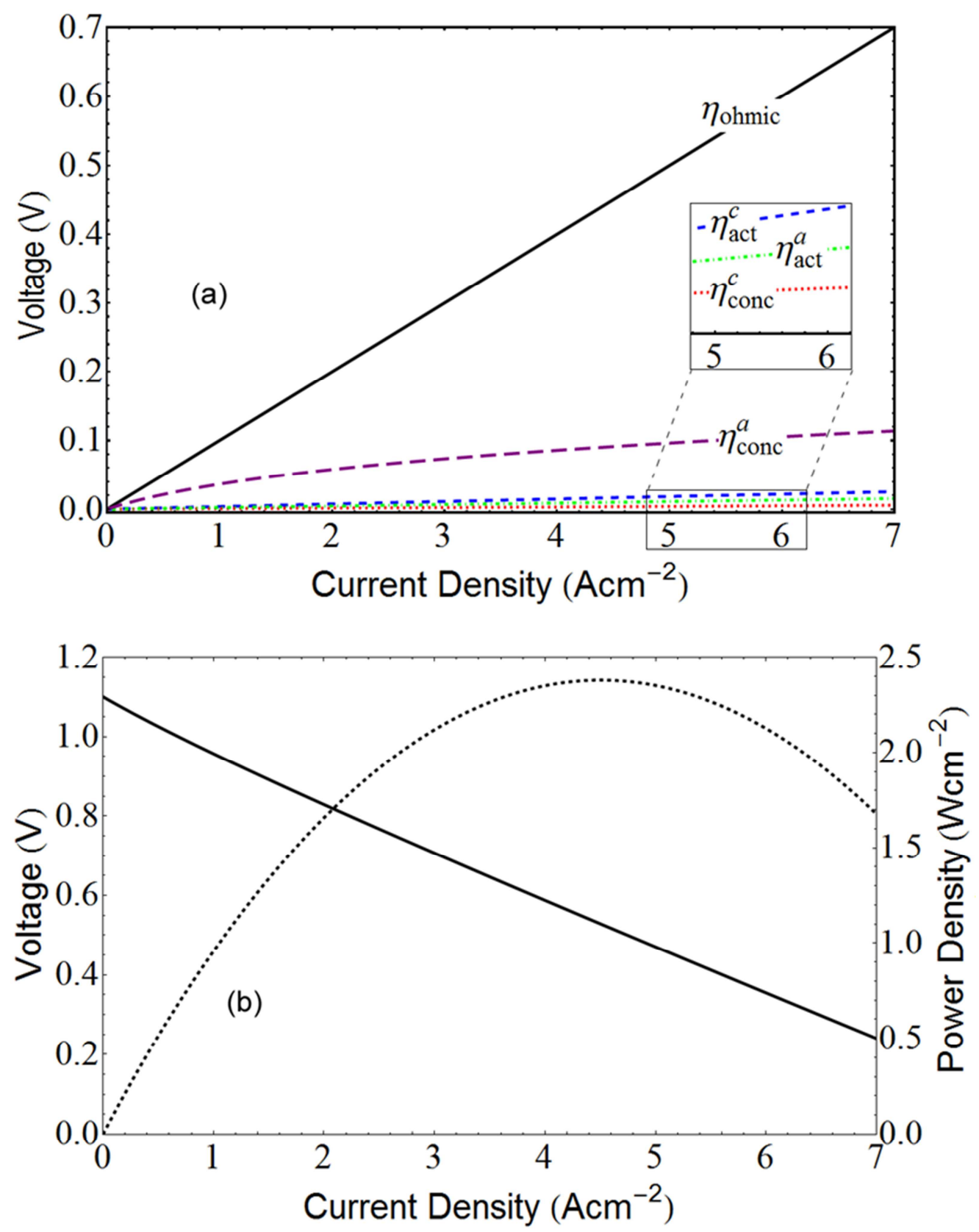

Figure 14: (a) Calculated polarizations at $800^{\circ} \mathrm{C}$ for a 5 layer cell with $8 \mu \mathrm{m}$ thick YSZ electrolyte, anode support thickness $0.5 \mathrm{~mm}$, cathode current collector thickness $50 \mu \mathrm{m}$, cathode and anode functional layer grain size of $0.02 \mu \mathrm{m}$ and functional layer thicknesses of $15 \mathrm{~d}=0.3 \mu \mathrm{m}$. The anode concentration polarization is lower than in Figure 13(a) because of the smaller anode support thickness. The ohmic resistance is $0.1 \Omega \mathrm{cm}^{2}$. The ohmic polarization dominates over the entire current density range. (b) The corresponding voltage vs. current density and power density vs. current density plots. 

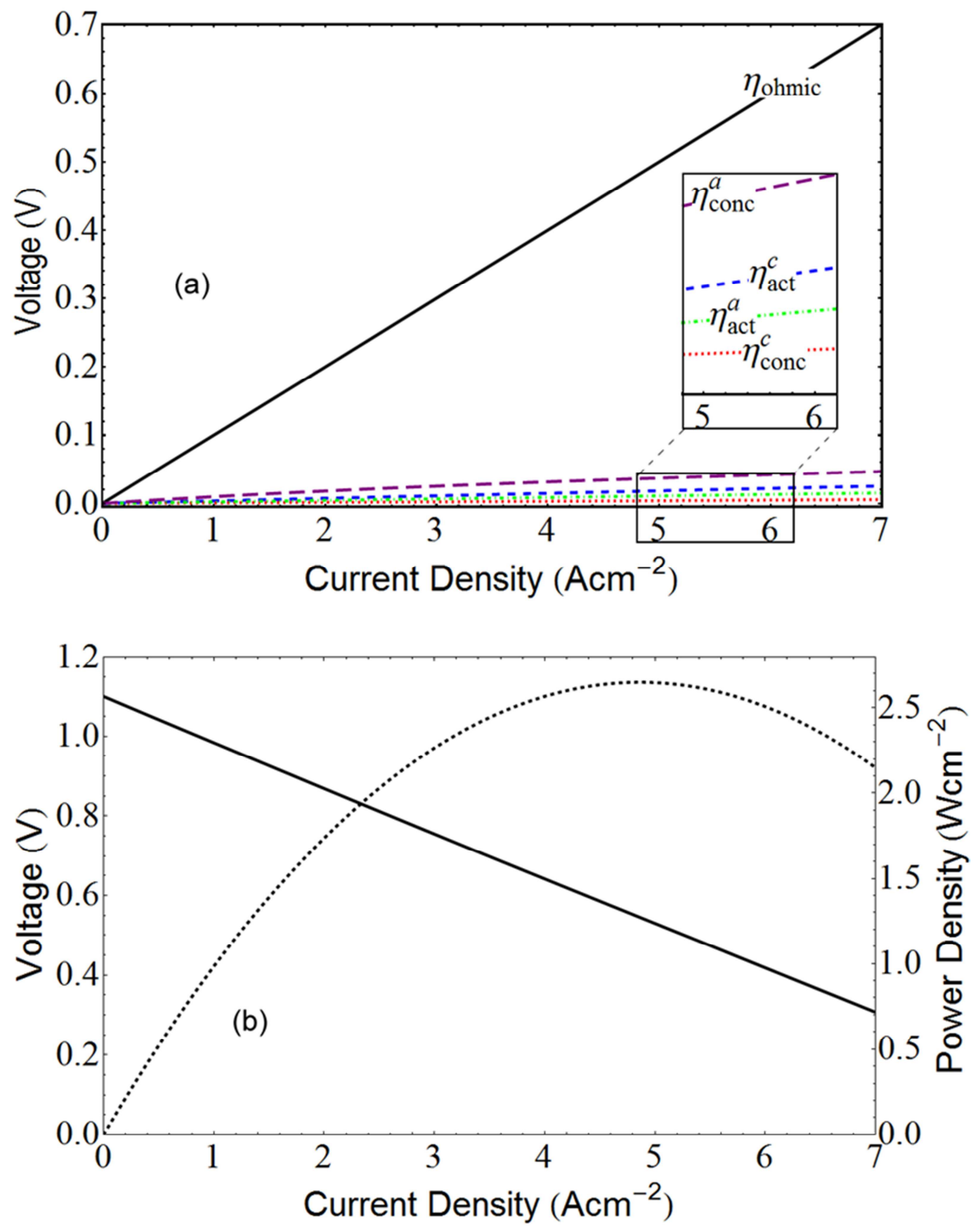

Figure 15: (a) Calculated polarizations at $800^{\circ} \mathrm{C}$ for a 5 layer cell with $8 \mu \mathrm{m}$ thick YSZ electrolyte, anode support thickness $0.1 \mathrm{~mm}$, cathode current collector thickness $50 \mu \mathrm{m}$, cathode and anode functional layer grain size of $0.02 \mu \mathrm{m}$ and functional layer thicknesses of $15 \mathrm{~d}=0.3 \mu \mathrm{m}$. The anode concentration polarization is lower than in Figure 14(a) because of the smaller anode support thickness. The ohmic resistance is $0.1 \Omega \mathrm{cm}^{2}$. The ohmic polarization dominates over the entire current density range. (b) The corresponding voltage vs. current density and power density vs. current density plots. 


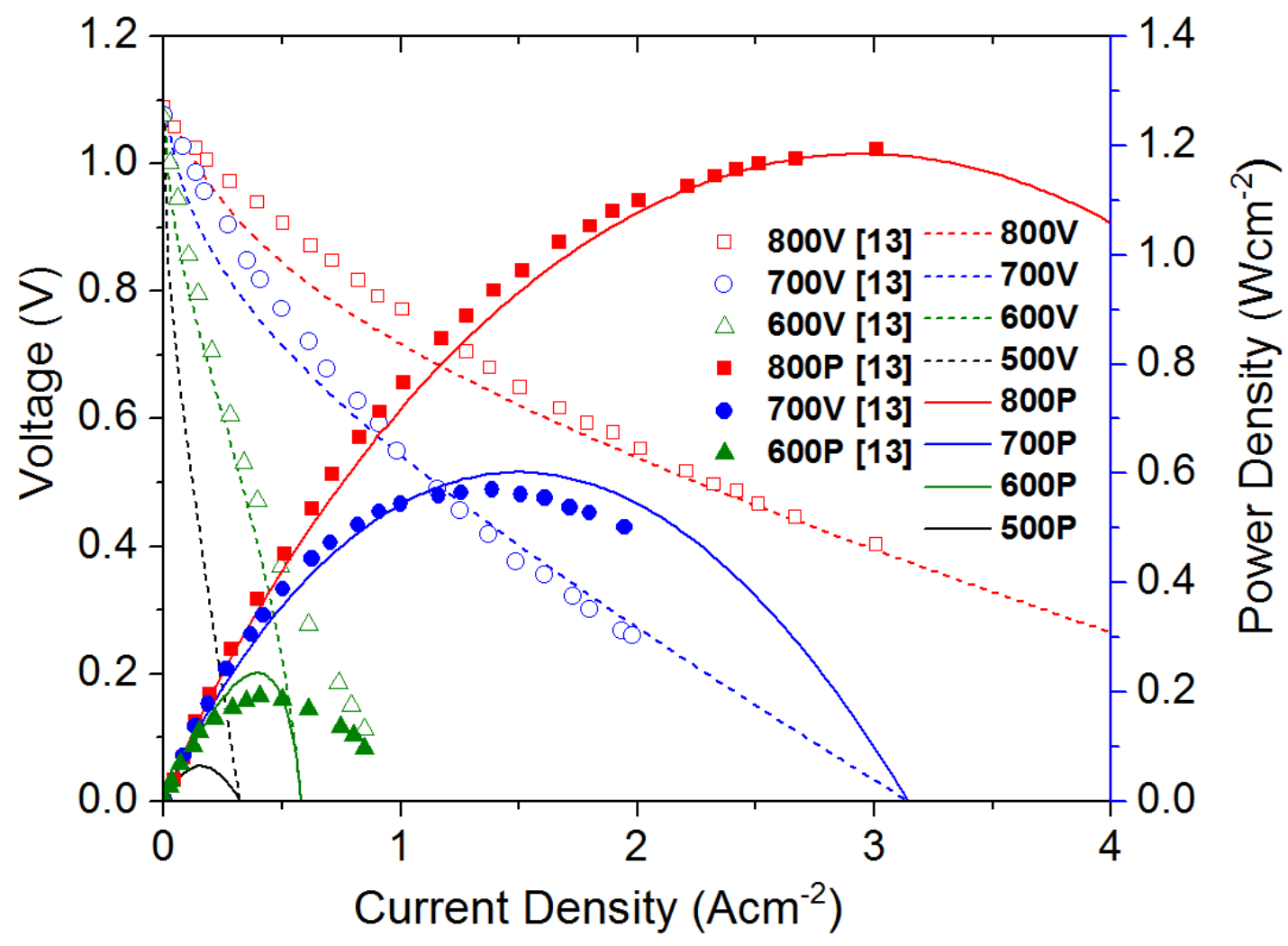

Figure 16: A comparison of experimental cell tests measurements from Zhao and Virkar [13] (symbols) with calculated performance curves using measurements made on cell materials and cell components, and using the parametric model. 


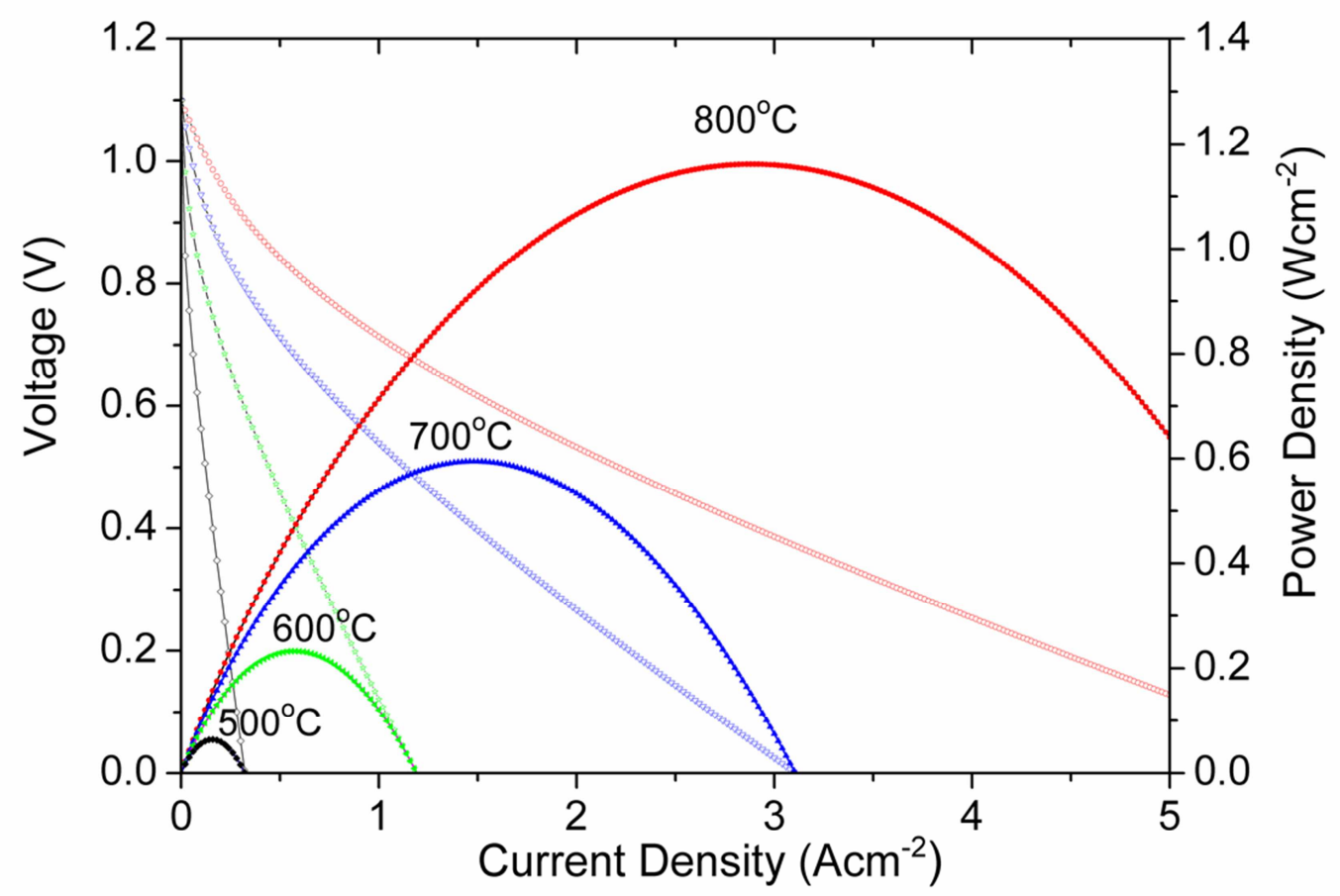

Figure 17: Calculated performance curves as a function of temperature for a cell with YSZ electrolyte of $8 \mu \mathrm{m}$ in thickness and electrode grain size of $2 \mu \mathrm{m}$. 


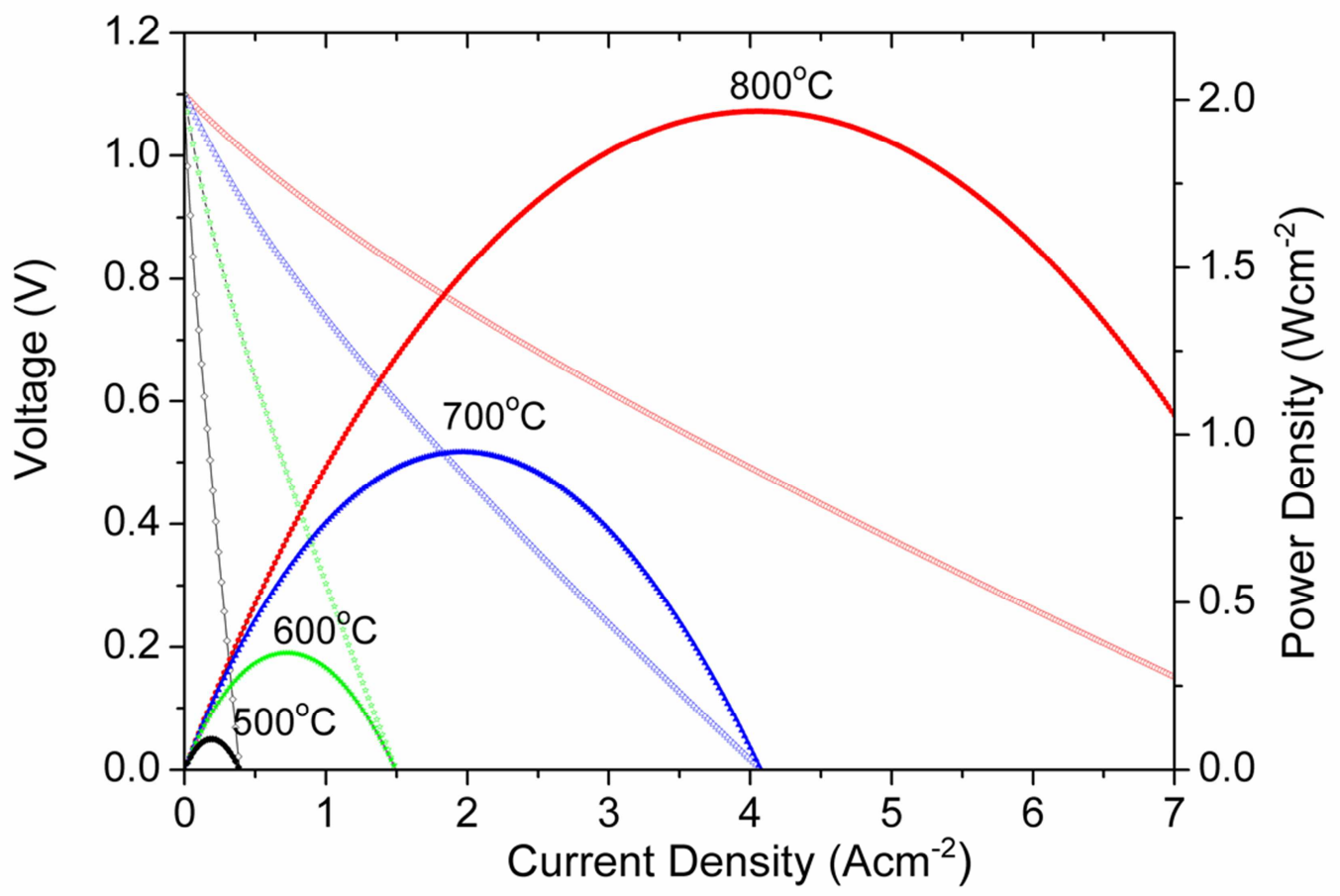

Figure 18: Calculated performance curves as a function of temperature for a cell with YSZ electrolyte of $8 \mu \mathrm{m}$ in thickness and electrode grain size of $0.2 \mu \mathrm{m}$. 


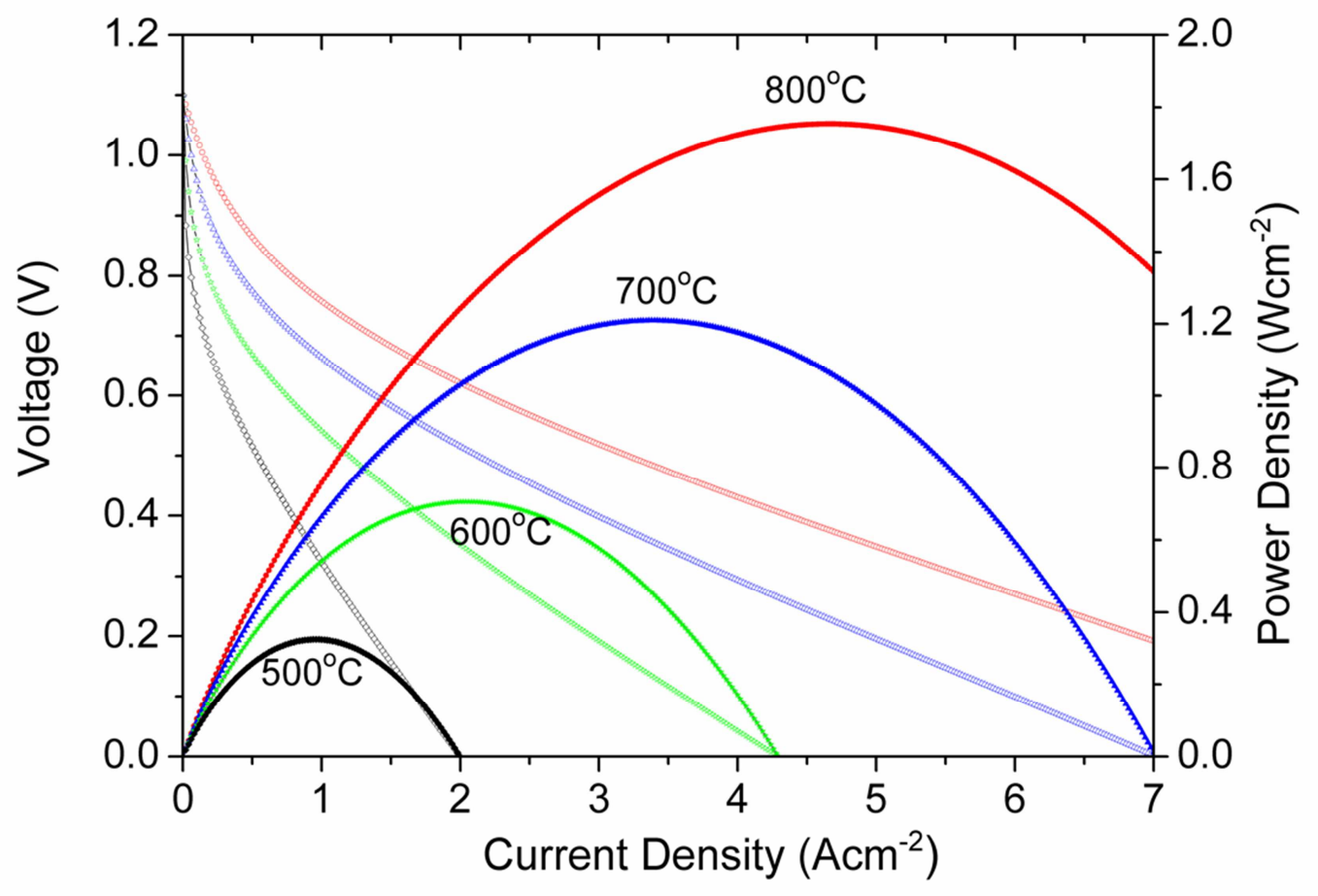

Figure 19: Calculated performance curves as a function of temperature for a cell with GDC electrolyte of $8 \mu \mathrm{m}$ in thickness and electrode grain size of $2 \mu \mathrm{m}$. 


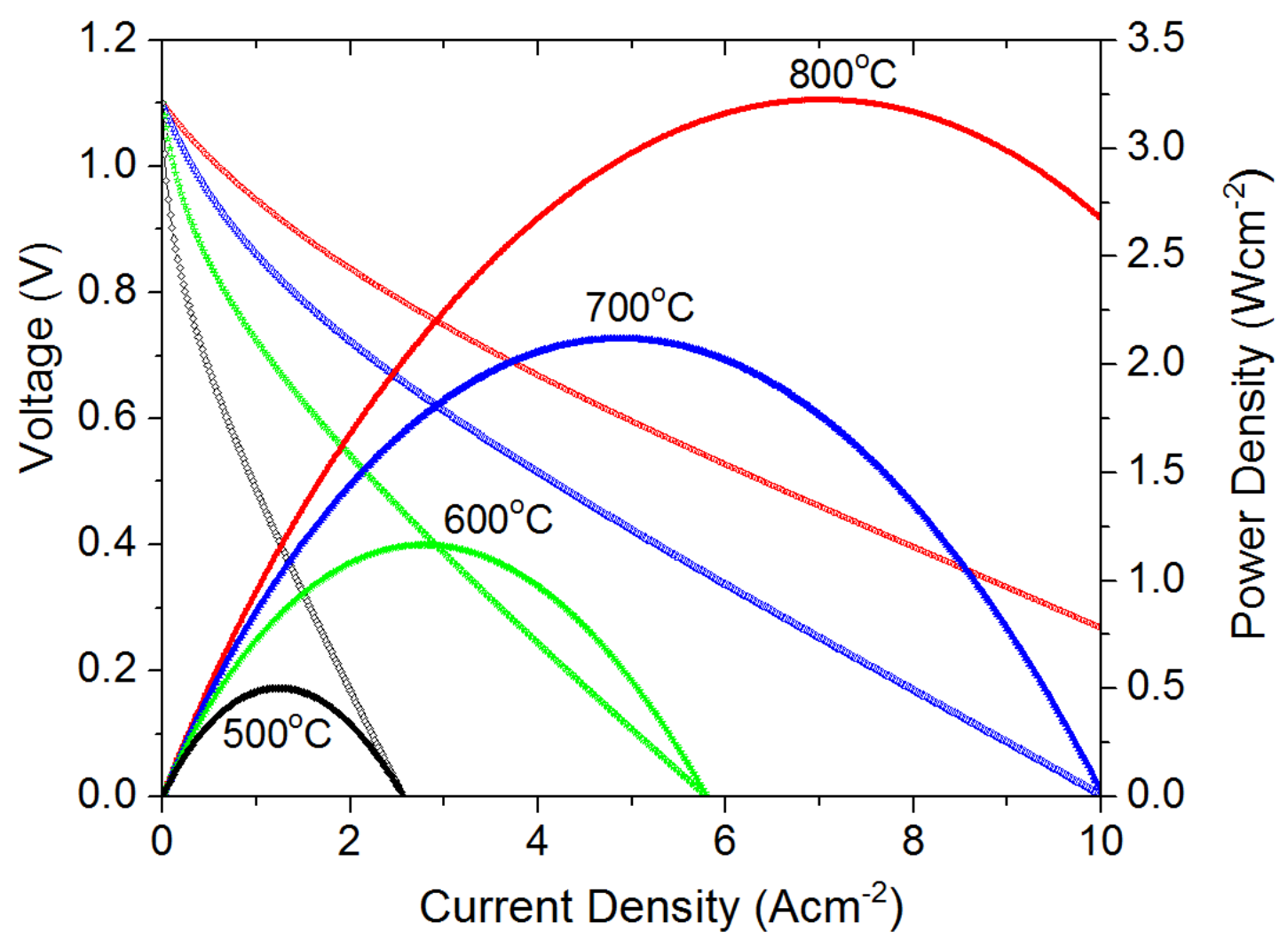

Figure 20: Calculated performance curves as a function of temperature for a cell with GDC electrolyte of $8 \mu \mathrm{m}$ in thickness and electrode grain size of $0.2 \mu \mathrm{m}$. 